\title{
Proteomics and metabolomics - Current and future perspectives in clinical andrology
}

\author{
Manesh Kumar Panner Selvam ${ }^{1}$ (D) | Renata Finelli ${ }^{1}$ (D) | Ashok Agarwal $^{1}$ (D) | \\ Ralf Henkel ${ }^{1,2}$ (i)
}

\author{
${ }^{1}$ American Center for Reproductive \\ Medicine, Cleveland Clinic, Cleveland, $\mathrm{OH}$ \\ USA \\ ${ }^{2}$ Department of Medical Bioscience, \\ University of the Western Cape, Bellville, \\ South Africa

\section{Correspondence} \\ Ashok Agarwal, American Center for \\ Reproductive Medicine, Cleveland Clinic, \\ Mail Code X-11, 10681 Carnegie Avenue, \\ Cleveland, OH 44195, USA. \\ Email: agarwaa@ccf.org
}

\begin{abstract}
Proteomics and metabolomics are emerging as promising tools to investigate the molecular mechanisms associated with male infertility. Proteins and metabolites play a pivotal role in regulating the molecular pathways associated with physiological functions of spermatozoa. Semen analysis, physical examination and laboratory work up cannot identify the etiology of infertility in $30 \%-40 \%$ of cases, which are classified as idiopathic. Therefore, the application of proteomics and metabolomics in the field of andrology will aid to overcome the limitations of the standard semen analysis. Understanding the molecular pathways associated with male infertility will help in planning ad hoc treatments, contributing to the clinical management of infertile patients. In this review, proteomics and metabolomics studies on spermatozoa and seminal plasma are discussed with a focus on molecular biomarkers associated with male infertility-related conditions.
\end{abstract}

\section{KEYWORDS}

biomarker, male infertility, mass spectrometry, metabolomics, proteomics

\section{1 | INTRODUCTION}

The evaluation of semen quality has been based on the results provided by the standard semen analysis since its introduction in the andrological practice. However, semen parameters do not determine the true fertility potential of an individual in 15\% of cases (Hamada, Esteves, Nizza, \& Agarwal, 2012), while physical examination, laboratory work and semen analysis fail to identify the etiology in $30 \%$ $40 \%$ of patients, those are classified as idiopathic male infertility (Bracke, Peeters, Punjabi, Hoogewijs, \& Dewilde, 2018). Proteomics and metabolomics are the two new emerging -OMICS platforms used for the identification of new markers to define the male fertility potential, with an increasing number of publications over the last two decades (Agarwal, Baskaran, Panner Selvam, Barbarosie, \& Master, 2020; Baskaran et al., 2019).

Complete profiling of proteins present in a tissue or a cell is defined as proteomics. Shotgun or bottom-up approaches are the most widely used in the field of proteomics, and they can detect more than 1,000 proteins in a given sample. In the field of male infertility, semen is the most commonly used biological fluid to evaluate the fertility status of men. Semen contains cellular and noncellular components, that is spermatozoa and seminal plasma, which can be investigated by applying proteomics techniques (Jodar, SolerVentura, \& Oliva, 2017; Panner Selvam \& Agarwal, 2018; Sinha, Singh, \& Yadav, 2017). Amaral et al. used a data mining approach to identify 6,198 proteins in human spermatozoa (Amaral, Castillo, Ramalho-Santos, \& Oliva, 2014), whereas 2064 proteins were identified in the seminal plasma (Jodar et al., 2017). Considering that spermatozoa are transcriptionally and translationally inert, they rely on proteins for their functional activity. Defects in the normal physiological functions of spermatozoa are observed due to alterations in the spermatozoa and seminal plasma proteome, and they are associated with male infertility conditions such as varicocele (Agarwal, Sharma, Durairajanayagam, Ayaz et al., 2015; Agarwal, Sharma, Durairajanayagam, Cui, et al., 2015; Agarwal, Sharma, Harlev, \& Esteves, 2016; Belardin et al., 2016; Mariana Camargo, Intasqui, \& Bertolla, 2016; Samanta et al., 2018), idiopathic infertility (Herwig et al., 2013; Hetherington et al., 2016; Shen, Wang, Liang, 
\& He, 2013), unexplained male infertility (UMI) (Azpiazu et al., 2014; Liu, Liu, et al., 2018; McReynolds et al., 2014; Xu et al., 2012), elevated oxidative stress (Ayaz et al., 2015; Hamada et al., 2013; Sharma et al., 2013) and testicular cancer (Agarwal, Tvrda, et al., 2015; Dias, Agarwal, Pushparaj, Ahmad, \& Sharma, 2018). Key proteins associated with sperm functions such as hyperactivation, capacitation, acrosome reaction and the fertilization process can be used as non-invasive biomarkers in the pathophysiology of male infertility.

\section{2 | TECHNIQUES IN PROTEOMICS}

Sperm proteins are detected and identified using different proteomic techniques. The conventional approach includes the separation of the extracted spermatozoa or seminal plasma proteins based on properties such as molecular weight and isoelectric point using two-dimensional (2D) gel electrophoresis. A total of 98 human sperm proteins were separated using 2D-gel electrophoresis and identified by matrix-assisted laser desorption/ionisation time-offlight (MALDI-TOF) technique. These proteins were involved in transcription, energy production and protein synthesis (MartínezHeredia, Estanyol, Ballescà, \& Oliva, 2006). Difference gel electrophoresis (DIGE), an improved version of 2D-gel electrophoresis technique, is able to identify differentially expressed proteins (DEPs) with a minimum error of $<10 \%$ (Gupta, Ghulmiyyah, Sharma, Halabi, $\&$ Agarwal, 2014). The expression profile of the proteins is determined based on the intensity of Cy 3 and $\mathrm{Cy} 5$ dyes using automated image analysis software.

Low sensitivity and the inability to detect less abundant proteins or low number of proteins are some of the limitations of conventional proteomic techniques. These limitations were overcome by using advanced high-throughput techniques such as MALDI-TOF and LC-MS/MS (liquid chromatography-tandem mass spectrometry). These instruments can even detect low abundance peptides present in a sample with low protein concentration. Johnston et al. used in-gel digestion-based LC-MS/MS approach to identify 1,760 sperm proteins (Johnston, Wooters, Kopf, Qiu, \& Roberts, 2005), and the same approach was widely used to profile the spermatozoa of infertile men (Cao et al., 2018; Dias et al., 2018; Giacomini et al., 2015; Liu, Liu, et al., 2018).

Additional purification of seminal plasma is not required as they are rich in proteins and are readily available for proteomic experiments. Semen samples undergo purification and processing steps prior to the extraction of sperm proteins. Semen samples are subjected to different types of processing techniques such as single gradient centrifugation, double gradient centrifugation or multilayer gradient centrifugation to separate the spermatozoa from the seminal plasma. Several studies have used a density gradient centrifugation step to remove round cells and immature germ cells from semen samples to isolate a pure sperm fraction (Amaral, Paiva, et al., 2014; Intasqui et al., 2013; Martínez-Heredia et al., 2006; Wang et al., 2014, 2018). Further, proteomic studies on round cells and spermatozoa revealed that the influence of round cell proteins as contaminant in the sperm proteome was insignificant or very negligible (Panner Selvam, Agarwal, Dias et al., 2019; Panner Selvam, Agarwal, Dias, Martins, \& Samanta, 2019). The presence of these round cell proteins does not interfere with the bioinformatics results related to the molecular pathways associated with sperm function.

In general, extraction of proteins using RIPA buffer provides maximum yield of proteins compared to other techniques such as sonication. Incubation of spermatozoa overnight with RIPA buffer results in the lysis of sperm membrane and release of proteins. Subsequently, the proteins are pelleted and washed 3 times with RIPA solution to remove cell debris. The concentration and purity of the sperm proteins are determined before they are subjected to proteomic analysis. A known amount of protein is separated using $4 \%$ to $15 \%$ SDS-PAGE, and in-gel digestion of the separated proteins is done using trypsin. Digested peptides are eluted from the gel and injected into mass spectrometry (Glish \& Vachet, 2003). The instrument detects the proteins or peptides based on mass/charge ratio $(\mathrm{m} / \mathrm{z})$ with a very low false discovery rate. Enrichment of sperm proteins by immunoprecipitation is the most preferred protocol for purifying the acetylated, methylated and phosphorylated proteins for post-translational modification studies. Other advanced techniques such as MALDI-TOF and SELDI-TOF (surface-enhanced laser desorption/ionisation time-of-flight) are also used to detect the sperm proteins (Bracewell-Milnes et al., 2017; Rødgaard, Heegaard, \& Callesen, 2015).

Computational software such as SEQUEST, Mascot X!, Tandem and MaxQuant (Zhou, Zhou, \& Guo, 2013) is used to identify the peptides and proteins. These computational tools perform a complete scan of proteins detected by MS and compare it with already available global databases for the human proteome. Further, the proteins are categorised as DEPs based on spectral counts (SC) and abundance of each protein. Bioinformatic analysis provides insight into the functional and molecular mechanisms based on the proteomic data (Lan et al., 2003). Gene ontology (GO) analysis of the proteins provides information about their localization, distribution and biological functions. Protein-protein interactions and defective molecular pathways can be identified using sophisticated programs such as Ingenuity Pathway Analysis (IPA) and Metacore ${ }^{\text {TM }}$. STRING (Search Tool for the Retrieval of Interacting Genes/Proteins) analysis is commonly performed to display the link between the proteins (Agarwal et al., 2014).

\section{3 | PROTEOMICS IN DECIPHERING KEY PROTEINS ASSOCIATED WITH MALE REPRODUCTION}

Alteration in the expression profile of key proteins involved in the cellular and molecular pathways in the spermatozoa can be identified using proteomics (du Plessis, Kashou, Benjamin, Yadav, \& Agarwal, 2011). Particularly, proteomics can be applied to analyse the whole sperm proteome as well as protein expression in subcellular compartments. Furthermore, the same approach can be used for 
seminal plasma and testicular tissue, as explained in the subsequent sections.

\subsection{Whole sperm proteomics}

Several investigators have characterised the proteome from whole sperm cells in normozoospermic men. In 2006, Martinez-Heredia et al. identified 98 proteins in normozoospermic men by using 2-DE and MALDI-TOF MS analysis, mainly structural proteins or involved in regulation of energy metabolism, protein synthesis, cellular cycle, apoptosis and cellular movement, as well as in the response to the oxidative stress (Martínez-Heredia et al., 2006). Nowicka-Bauer et al. identified 73 proteins involved in energy metabolism using 2-DE and MS (Nowicka-Bauer et al., 2018). They also reported 25 proteins for the first time in spermatozoa, including ANXA7, a calcium-dependent phospholipid binding protein localized in the sperm membrane, and c14orf105, still uncharacterized protein in the sperm nucleus. Proteomic profile of the spermatozoa differs among its subsets. Global proteomics has been conducted on different fractions of spermatozoa (mature and immature) from fertile and infertile men (Cui, Sharma, \& Agarwal, 2016; Samanta, Sharma, Cui, \& Agarwal, 2018). A higher expression of proteins involved in protein biosynthesis, transport and ubiquitination as well as in the cellular response to oxidative stress was observed in immature spermatozoa (Cui et al., 2016). In spermatozoa of infertile men, the most mature sperm fraction showed an altered expression of proteins involved in energy-related signalling cascade as well as protein folding (Samanta et al., 2018).

Whole sperm proteomics involves the characterization and profiling of proteins and peptides extracted from the spermatozoa. It has been investigated in several infertility-related conditions. Intasqui et al. analyzed the proteomic profile of spermatozoa in men with primary and secondary infertility (Intasqui, Agarwal, Sharma, Samanta, \& Bertolla, 2018), and reported a total of 117 DEPs when compared to proven fertile men. Furthermore, BAG6 and HIST1H2BA were proposed as potential markers for male infertility. These proteins are involved in post-translational modifications and folding of proteins as well as in histones replacement by protamines, respectively (Intasqui et al., 2018).

\subsection{1 | Subcellular proteomics}

Proteomics studies on the whole cellular lysate do not provide sufficient information regarding function of the proteins localized in subcellular compartments or organelles of spermatozoa. Proteomic analysis of the proteins selectively extracted from the organelles of spermatozoa provides further information about the subcellular metabolism (Sadowski et al., 2006). In fact, the differential expression of proteins in subcellular compartments such as nucleus, acrosome and flagella is directly related to the function of spermatozoa (Amaral et al., 2013; Baker et al., 2013; Gu et al., 2011; Kim et al., 2007; de
Mateo, Castillo, Estanyol, Ballescà, \& Oliva, 2011; Naaby-Hansen \& Herr, 2010; Stein, Go, Lane, Primakoff, \& Myles, 2006). The sperm nuclear proteome is extracted by treatment of the sperm cells with the detergent cetyl trimethyl ammonium bromide (CTAB), to avoid any contamination from the flagella, mitochondria and acrosome region. De Mateo et al. analysed the nuclear proteins by 2D-PAGE and LC-MS/MS (de Mateo et al., 2011) and identified that histones and chromatin-related proteins are involved in the epigenetic regulation of spermatozoa, fertilisation and embryo development. A total number of 521 and 721 proteins were reported to be uniquely expressed in the head and tail of spermatozoa, respectively (Baker et al., 2013). Specifically, the flagellar subcompartment was enriched in metabolic proteins involved in pathways associated with the energy generation, such as glycolysis, gluconeogenesis, the Krebs cycle and the oxidative phosphorylation as well as metabolism of fatty acids and amino acids, in agreement with the role of sperm tail in motility (Amaral et al., 2013; Kim et al., 2007). Proteins localized in the sperm head were mainly proteases, kinases and proteins involved in signalling pathways (Baker et al., 2013), whereas proteins mediating capacitation, acrosomal reaction and oocyte binding were also described (Gu et al., 2011; Naaby-Hansen \& Herr, 2010; Stein et al., 2006).

\subsection{2 | Sperm surface proteomics}

Sperm recognize the zona pellucida with the help of binding proteins expressed on sperm surface, which also regulate the induction of the acrosome reaction. Therefore, the proteins expressed on the membrane are essential in the zona penetration and fertilization. Furthermore, membrane composition is the result of the complex process involved in spermatogenesis and its analysis can be informative regarding the sperm differentiation and maturation. Sperm cells are first lysed to purify the plasma membrane proteins. This can be achieved by sonication or nitrogen cavitation techniques in combination with differential centrifugations to isolate the different cellular component (Zhou \& Philips, 2017). It is possible to selectively extract peripheral membrane proteins by treating the lysate with high concentration of salt or specific detergents to extract the lipid drafts. Shetty et al. analyzed the sperm surface proteome in order to identify candidates for generating a contraceptive vaccine (Shetty et al., 2001). Expression of angiotensin-converting enzyme (ACE) on sperm membrane was identified by labelling proteins with sulfoNHS-LC-biotin before 2D-gel electrophoresis and microsequencing. Domagala et al. applied proteomics techniques to identify immunoreactive antigens on sperm surface (Domagala, Pulido, Kamieniczna, Kurpisz, \& Herr, 2011), in order to decipher the proteins involved in the generation of an autoimmune response against spermatozoa. They confirmed the expression of sperm antigens, such as L-lactate dehydrogenase $\mathrm{C}$ chain and GAPDH2, as well as other new intrinsic and surface antigens, such as the clathrin heavy chain.

Lipid drafts are domains in the plasma membrane where proteins involved in the same pathway co-localize in association with cholesterol and sphingolipids. Nixon et al. reported that these 
proteins particularly mediate the binding to the zona pellucida and the further fusion of sperm membrane with the oolemma (Nixon et al., 2011). A total number of 124 proteins were identified in the sperm membrane lipid drafts by using a nano-LC/MS/MS approach. ACE, integrin beta-2, sperm adhesion molecule 1, SPA17 and arylsulphatase $A$ proteins involved in sperm-oocyte binding and adhesion, while proteins involved in cellular signalling, protein folder and intracellular transfer were identified on sperm membrane (Nixon et al., 2011).

\subsection{Seminal plasma proteomics}

Seminal plasma is a heterogeneous fluid composed by secretions from organs and glands of the reproductive male tract. It has been estimated that $23 \%$ of the studies on proteomics in the male reproductive field in the last 20 years have been conducted on seminal plasma (Agarwal et al., 2020). The first study analyzing the seminal proteome in healthy men was published in 2006 (Pilch \& Mann, 2006). By using LC-MS/MS analysis, authors reported the expression of 923 proteins, such as FN1, SEMG1 and 2, lactoferrin and laminin. When the seminal proteome was analysed by HPLC coupled with MS, 83 proteins were reported to be commonly expressed in 5 fertile men, all of them involved in the male fertility-related pathways, such as SEMG I and II (participating in the formation of coagulum after the ejaculation), lactoferrin (acting as an immune-modulatory protein and also having antibacterial and antioxidant properties) and clusterin (previously described to be involved in sperm agglutination) (Milardi et al., 2012). By classifying normozoospermic patients based on the values of sperm mitochondrial activity, acrosome integrity and sperm DNA fragmentation, Intasqui et al. proposed a set of seminal biomarkers associated with each of these alterations (Intasqui et al., 2016). Alterations of mitochondrial activity were associated with an increased expression of ANXA7, glutathione S-transferase Mu3 and endoplasmic reticulum resident protein 44; increased expression of the phospholipid transfer protein was associated with acrosome defects, while CRISPLD1, CRISPLD2 and retinoic acid receptor responder protein 1 were proposed as markers of sperm DNA damage.

A variation in seminal proteome was observed in normozoospermic patients classified according to the levels of semen lipid peroxidation, measured by thiobarbituric acid assay (Intasqui et al., 2015). By using LC-MS/MS analysis, oxidative stress was reported to influence seminal proteome, by inducing an increased expression of proteins related to the biosynthesis of unsaturated fatty acids, and response to oxidative, immune and heat stress. These preliminary observations have been further strengthen by the report of 44 DEPs in fertile men classified regarding the concentration of seminal ROS, detected by chemiluminescence (Dias et al., 2019). Particularly, fertile men having high ROS concentration expressed higher levels of SOD1 and PRDX4, antioxidants systems to counterbalance the oxidant levels and proteins involved in the degradation of defective proteins.

\section{3 | Testicular proteomics}

Proteomic research conducted on testicular tissue is very limited. Very few articles have been published using testicular tissue in the last 20 years (Agarwal et al., 2020). Testicular proteome provides substantial understanding about the cellular signalling pathways that are significantly altered in pathological conditions, such as obstructive and non-obstructive azoospermia, and testicular cancer (Alikhani et al., 2017; Leman et al., 2009; Liu et al., 2013). Future proteomics studies on testicular tissue will help in the investigation of proteins involved in spermatogenesis and to identify novel targets for treatment of male infertility ( $\mathrm{Li}$ et al., 2011).

\section{4 | THE IMPACT OF CRYOPRESERVATION ON SPERM PROTEOMICS}

Semen cryopreservation is a procedure performed routinely to preserve the spermatozoa for future use in ART procedures. Cryopreservation has been correlated with reduced semen quality, particularly decreased motility, viability and acrosome integrity (Ozkavukcu, Erdemli, Isik, Oztuna, \& Karahuseyinoglu, 2008). Bogle et al. also reported the alteration of sperm proteome depending on the use of cryoprotectant (protein-free cryosperm medium) and the freezing/thawing procedure itself, potentially due to the induction of protein degradation and osmotic stress (Bogle et al., 2017). Proteomics analysis of cryopreserved spermatozoa showed altered expression of proteins involved in reproductive function pathways, such as energy metabolism (ACO2, ENO1), the maintenance of cell surface integrity (vimentin) and the flagellar structural integrity (TEKT1) (Wang et al., 2014). Also, higher levels of global tyrosine phosphorylation were reported in frozen spermatozoa, in association with alteration of sperm motility, sperm functions and a premature induction of capacitation (Wang et al., 2014). The investigation of the altered pathways in spermatozoa after cryopreservation may be of outstanding importance for the creation of specific cryoprotectants having a low impact on sperm physiology and potentially improve the reproductive outcomes after ART.

\section{5 | PROTEOMICS IN PROGNOSIS AND DIAGNOSIS OF MALE INFERTILITY}

Over the last two decades, an increasing number of studies has been published about proteomics in male infertility-related clinical scenarios such as varicocele, idiopathic infertility, testicular cancer, UMI and sperm abnormalities-related conditions (Agarwal et al., 2020). Research is mainly aimed to decipher the molecular mechanisms affecting the reproductive function of infertile men and to identify potential biomarkers for the diagnosis and treatment in clinical setting. 


\section{1 | Potential biomarkers of varicocele}

Varicocele is a vascular disease characterised by the enlargement of the pampiniform venous plexus (Miyaoka \& Esteves, 2012). Few global proteomic studies have reported the key proteins and the altered molecular mechanisms in male infertility-associated varicocele (Agarwal, Sharma, Samanta, Durairajanayagam, \& Sabanegh, 2016; Ayaz et al., 2015; Panner Selvam \& Agarwal, 2019; Panner Selvam, Agarwal, \& Baskaran, 2019; Samanta et al., 2018). Reduced expression of proteins involved in mitochondrial (ATPase1A4) and cytoskeleton (SPA17) functionality and structure, as well as related to sperm functions (HSPA2, APOA1), was reported in varicocele sperm samples (Agarwal, Sharma, Samanta, et al., 2016; Hosseinifar et al., 2013; Samanta et al., 2018).

Panner Selvam \& Agarwal (2019) showed an altered expression of 28 seminal plasma proteins in varicocele patients, mainly associated with oxidative stress response and sperm-oocyte membrane fusion, while other studies reported an alteration of seminal proteins related to sperm maturation, sperm motility and capacitation (Fariello et al., 2012; Zylbersztejn et al., 2013). Varicocele correction resulted in an improved expression of seminal plasma proteins involved in oxidative stress response, protein stabilization and gluconeogenesis (Fariello et al., 2012; Zylbersztejn et al., 2013; Camargo, Intasqui, \& Pimenta Bertolla, 2016). Moreover, the expression of three proteins (HSPA5, SOD1 and ATP5D) involved in protein folding, oxidative stress response and energy generation increased after varicocele correction (Hosseinifar et al., 2014), with a shift towards the homeostasis (Camargo et al., 2013; Del Giudice et al., 2013).

A severe alteration of the sperm proteome was observed in bilateral varicocele compared to unilateral varicocele (Agarwal, Sharma, Durairajanayagam, Cui, et al., 2015) as well as proteins associated with inflammatory response such as IL-6 and Jak-STAT pathways (Panner Selvam, Agarwal, Pushparaj, Baskaran, \& Bendou, 2019).

Proteins such as ENKUR, SEMG1, SEMG2, SPAM1 and CABYR, involved in calcium transduction machinery, capacitation, acrosome reaction and in the formation of semen coagulum, were significantly overexpressed in bilateral varicocele patients (Agarwal, Sharma, Durairajanayagam, Cui, et al., 2015). Moreover, the overexpressed PRDX2 and FASN and the reduced FN1 seminal plasma proteins were suggested to differentiate bilateral from unilateral patients (Panner Selvam et al., 2019). Sperm proteins such as CRISP2 and ARG2 were expressed uniquely in unilateral varicocele patients (Agarwal, Sharma, Durairajanayagam, Ayaz et al.,2015). CRISP2 is involved in calcium fluxes during the capacitation, while ARG2 was negatively associated with sperm concentration and positively with sperm motility (Cohen et al., 2011; Elgün, Kaçmaz, Sen, \& Durak, 2000). Moreover, GNPDA1 was expressed only in unilateral patients, being involved in calcium oscillation triggering oocyte activation and embryo development (Agarwal, Sharma, Durairajanayagam, Cui, et al., 2015). The overexpression of proteins involved in antioxidant systems was also reported, suggesting the establishment of a reductive stress microenvironment in unilateral varicocele patients (Swain et al., 2019).

\subsection{Potential biomarkers of unexplained (UMI) and idiopathic male infertility}

$\mathrm{UMI}$ is defined as a condition in which the semen parameters are normal (according to $\mathrm{WHO} 5^{\text {th }}$ edition guidelines) but the cause of infertility is unknown (Hamada et al., 2012). Idiopathic infertile patients are those with altered semen parameters with an unknown cause (Aktan et al., 2013). Proteomics analysis of spermatozoa from infertile normozoospermic men revealed underexpression of proteins (CRISP2, NME5, TSSK2, MYCBP, NDRG3, SPATA24, ROPN1L) involved in development/functions of male gametes (McReynolds et al., 2014). Moreover, proteins involved in response to the stress (HSPA2, HSPA5, STIP1, CLU) resulted to be overexpressed in case of poor blastocyst development and reduced implantation rate after in vitro fertilisation, suggesting them as potential molecular biomarkers for UMI (McReynolds et al., 2014). Other proteins such as the ANXA2, SPA17 and SERPINA5 were differentially expressed and proposed as potential biomarkers in UMI condition (Panner Selvam et al., 2019). SPA17 is involved in the acrosome reaction and oocyte fertilization (Chiriva-Internati et al., 2009), while SERPINA5 is mainly expressed in the head of spermatozoa, being involved in the sperm-oocyte binding (Yang \& Geiger, 2017). Underexpression of both proteins (SPA17 and SERPINA5) may significantly affect the male fertility potential. On the other hand, ANXA2 is reportedly overexpressed during abnormal ubiquitination (Deng, Jing, Xing, Hou, \& Yang, 2012) and may affect the sperm functions. The proteins clusterin, epididymal secretory protein E1 (HE1) and PSA were proposed as seminal biomarkers for success in unexplained infertile couples undergoing IVF (Kanannejad \& Gharesi-Fard, 2019). These proteins are correlated with the sperm quality. Clusterin protects the spermatozoa from oxidative stress and DNA damage, and regulates the sperm motility and viability (Salehi et al., 2013). HE1 is secreted by epididymis and plays a role in cholesterol transport (Girouard, Frenette, \& Sullivan, 2008), while the prostatic PSA regulates semen liquefaction (Balk, Ko, \& Bubley, 2003).

Agarwal et al. reported the changes in the sperm proteome of idiopathic infertile men treated with antioxidant supplementation ( $\mathrm{FH}$ PRO for Men) (Agarwal et al., 2019). Besides the beneficial effect of FH PRO for Men on semen quality, it is also predicted to enhance the metabolic pathways involved in the energy production, spermatogenesis, sperm functions and fertilization as well as increase cellular response to oxidative stress (Agarwal et al., 2019).

\section{3 | Potential biomarkers of testicular cancer}

Testicular cancer is common in men of reproductive age (15-40 years old) (Chia et al., 2010). It arises from malignant transformation of germ cells in $95 \%$ of cases, further subcategorized in seminomas (50\%) and non-seminomas (50\%) (Adra \& Einhorn, 2017). Recently, Panner Selvam et al. reported an altered protein profile in spermatozoa of testicular cancer patients, particularly protein regulators of sperm motility, oocyte binding, capacitation and fertilization, and have suggested putative molecular biomarkers associated with each 
dysfunctional pathway (Panner Selvam, Agarwal, \& Pushparaj, 2019). Proteomic analysis of testicular cancer tissue has revealed proteins like PIWIL1 (involved in DNA methylation and RNA silencing) and TMPRSS12 (a serine protease) as markers of testicular tumour germ cells (Liu et al., 2013). Furthermore, glutathione S-transferase M3 was reported to be downregulated in case of seminoma and distinct polymorphisms associated with higher risk of cancer development (Zimmermann et al., 2006). Other putative markers identified in seminoma tissue by 2D-gel electrophoresis included the overexpression of GCP6 (microtubule nucleation) and CDK10 (cellular cycle regulator), as well as the underexpression of StarD7 (maintenance of the cellular shape) (Leman et al., 2009). Castillo et al. combined metal oxide affinity chromatography with LC-MS/MS to investigate testicular phosphoproteome and reported an overexpression of PAK4 protein in embryonal carcinoma (Castillo et al., 2019). PAK4 is involved in cellular proliferation, and its overexpression protects the cancer cells from the apoptosis.

\section{4 | Potential biomarkers of sperm abnormalities}

Proteomes have been analysed in several groups of sperm abnormalities. Protein pathways associated with sperm motility are compromised in asthenozoospermic patients (Hashemitabar, Sabbagh, Orazizadeh, Ghadiri, \& Bahmanzadeh, 2015). The DEPs identified in asthenozoospermic patients were mainly associated with energy and metabolism, movement and structural organisation, stress response, signalling and antioxidant activity (Martinez-Heredia, de Mateo, Vidal-Tboada, Ballesca, \& Oliva, 2008; Siva et al., 2010; Zhao et al., 2007). Hashemitabar et al. reported a decreased expression of proteins involved in the ATP synthesis, suggesting the oxidative phosphorylation as the main pathway in regulating sperm motility (Hashemitabar et al., 2015). Further, the absence of structural proteins such as ODF2 and tektin 4 in sperm flagella suggests cytoskeleton alteration as the main cause of asthenozoospermia (Shen et al., 2013). However, Zhao et al. reported higher levels of ODF proteins and a reduced expression of the $26 \mathrm{~S}$ protease regulatory subunit 7 in asthenozoospermic Asian cohort (Zhao et al., 2007), whereas the subunit PSMB3 component of proteasome complex was overexpressed in the European population (Martinez-Heredia et al., 2008), underlining difference in protein expression due to geographical origin. Moreover, lower levels of GRP78 in idiopathic asthenozoospermic patients may be involved in a reduced sperm binding to zona pellucida, with consequences on sperm capacitation and fertilization (Shen et al., 2013). In addition to protein expression, post-translational modifications of proteins can adversely affect the sperm physiology (Baker, Witherdin, Hetherington, Cunningham-Smith, \& Aitken, 2005). These include glycosylation, S-nitrosylation, sumoylation and phosphorylation (Lefièvre et al., 2007; Samanta, Swain, Ayaz, Venugopal, \& Agarwal, 2016; Vigodner et al., 2013; Wang et al., 2013). Particularly, phosphorylation regulates sperm maturation and capacitation (Ficarro et al., 2003). Asthenozoospermic spermatozoa showed a reduced level of protein phosphorylation, resulting in the alteration of the mitochondrial energy metabolism and fibrous sheath/cytoskeletal structure, and lower sperm motility (Chan et al., 2009; Parte et al., 2012).

Seminal proteins such as ECM1, TEX101 and NPC2 have been proposed to discriminate obstructive from non-obstructive azoospermia (Drabovich et al., 2013; Yamakawa, Yoshida, Nishikawa, Kato, \& Iwamoto, 2007). Freour et al. focused on the identification of biomarkers for the spermatozoa retrieval from testis in case of non-obstructive azoospermia and revealed higher expression of seminal LGALS3BP in men with successful TESE (Freour et al., 2013). Oligoasthenoteratozoospermic (OAT) patients showed altered seminal expression of proteins involved in metabolism and inflammation, stress response and proteins associated with binding, transporter, immune and hydrolase activities (Giacomini et al., 2015; Herwig et al., 2013; Liu, Wang, et al., 2018). Recently, Liu et al. proposed KLK3, LTF SERPINA1 and GAPDH as putative biomarkers to discriminate between OAT and normozoospermic patients (Liu, Wang, et al., 2018), besides the previously identified NPC2, M2BP and lipocalin-1 (Giacomini et al., 2015) (Table 1). Herwig et al. identified a panel of 46 proteins related to oxidative stress in patients with infertile idiopathic OAT (Herwig et al., 2013). These studies provided further insight into the molecular pathogenic mechanisms underlying OAT condition.

The proteome of globozoospermia, a rare genetic condition characterised by the absence of acrosome, has also been investigated. Comparative analysis of sperm proteome of globozoospermic patients against normozoospermic subjects revealed aberrant expression of 35 proteins involved in spermatogenesis, metabolism, cytoskeleton and sperm function (Alvarez Sedo', Rawe, \& Chemes, 2012; Liao, Xiang, Zhu, \& Fan, 2009). These included the overexpression of AKAP4 and actin, as well as the underexpression of enzymes of the Krebs cycle, tubulin and proteins associated with the outer dense fibres and acrosome membrane.

\section{OVERVIEW OF METABOLOMICS}

Metabolomics is one of most recent -OMICS techniques that was developed after genomics, transcriptomics and proteomics to analyse the entire metabolome, the final products of the metabolism within a biological system (Zhang, Sun, Wang, Han, \& Wang, 2012). The metabolites are small molecules, less than $1 \mathrm{kDa}$ derived from metabolic pathways, and include hormones, amino acids, lipids, carbohydrates and nucleotides. The composition of the metabolome determines the current phenotypic state of a cell and actively changes in response to cellular and extracellular stimuli, making metabolomics studies more informative than the other -OMICS approaches, particularly in the investigation of cellular response to exogenous stimuli or in case of pathology (Nicholson, Lindon, \& Holmes, 1999). The total estimate of metabolites is approximately 6,500 , which is significantly lower than the number of genes $(25,000)$, messenger RNAs $(100,000)$ and proteins $(1,000,000)$ present in a human cell. However, the development 
TABLE 1 Potential protein biomarkers in different male infertility conditions

\begin{tabular}{|c|c|c|c|}
\hline Condition & Sample & Results & Reference \\
\hline \multirow[t]{3}{*}{ Varicocele } & \multirow[t]{3}{*}{ Spermatozoa } & $\begin{array}{l}\text { Heat shock proteins, mitochondrial and } \\
\text { cytoskeleton proteins are mainly affected by } \\
\text { varicocele disease } \\
\text { Proposed markers to discriminate between } \\
\text { varicocele and healthy patients: } \\
\text { PKAR1A, AK7, CCT6B, HSPA2, ODF2, } \\
\text { ATPase1A4, HSPA2, SPA17 and APOA1 }\end{array}$ & $\begin{array}{l}\text { (Agarwal, Sharma, Samanta, } \\
\text { Durairajanayagam, \& Sabanegh, 2015; } \\
\text { Hosseinifar et al., 2013) }\end{array}$ \\
\hline & & $\begin{array}{l}\text { Proposed markers to discriminate between } \\
\text { bilateral and unilateral varicocele: ENKUR, } \\
\text { SEMG1, SEMG2, SPAM1, CABYR, PRDX2, } \\
\text { FASN and FN1. } \\
\text { Proteins CRISP2, ARG2 and GNPDA1 uniquely } \\
\text { expressed in unilateral patients compared with } \\
\text { fertile controls }\end{array}$ & $\begin{array}{l}\text { (Agarwal, Sharma, Durairajanayagam, Cui, } \\
\text { et al., 2015; Ayaz et al., 2015; Panner } \\
\text { Selvam, Agarwal, \& Baskaran, 2019) }\end{array}$ \\
\hline & & $\begin{array}{l}\text { The expression of HSPA5, SOD1 and ATP5D } \\
\text { improves after varicocelectomy }\end{array}$ & $\begin{array}{l}\text { (Camargo et al., 2013; Del Giudice } \\
\text { et al., 2013; Hosseinifar et al., 2014) }\end{array}$ \\
\hline \multirow[t]{2}{*}{$\begin{array}{l}\text { Unexplained male } \\
\text { infertility (UMI) }\end{array}$} & Spermatozoa & $\begin{array}{l}\text { Proposed markers to discriminate between } \\
\text { UMI and fertile patients: SPA17, ANXA2 and } \\
\text { SERPINA5 }\end{array}$ & (Panner Selvam et al., 2019) \\
\hline & Seminal plasma & $\begin{array}{l}\text { Biomarkers for success in couples undergone } \\
\text { IVF: clusterin, epididymal secretory protein E1 } \\
\text { and PSA }\end{array}$ & (Kanannejad \& Gharesi-Fard, 2019) \\
\hline \multirow[t]{4}{*}{ Testicular cancer } & Spermatozoa & $\begin{array}{l}\text { Altered proteins in asthenozoospermic } \\
\text { testicular cancer spermatozoa: CCT3, ATP1A4, } \\
\text { ATP5A1 and UQCRC2 }\end{array}$ & (Panner Selvam et al., 2019) \\
\hline & \multirow[t]{3}{*}{ Testicular tissue } & $\begin{array}{l}\text { Proposed markers of testicular tumour germ } \\
\text { cell: PIWIL1 and TMPRSS12 }\end{array}$ & (Liu et al., 2013) \\
\hline & & $\begin{array}{l}\text { Glutathione S-transferase M3 was reported to } \\
\text { be downregulated in case of seminoma, while } \\
\text { GCP6, CDK10 and StarD7 overexpressed }\end{array}$ & $\begin{array}{l}\text { (Leman et al., 2009; Zimmermann } \\
\text { et al., 2006) }\end{array}$ \\
\hline & & $\begin{array}{l}\text { Overexpression of PAK4 protein in embryonal } \\
\text { carcinoma }\end{array}$ & (Castillo et al., 2019) \\
\hline \multirow[t]{2}{*}{ Azoospermia } & \multirow[t]{2}{*}{ Seminal plasma } & $\begin{array}{l}\text { ECM1, TEX101 and NPC2 proteins were } \\
\text { suggested for the discrimination of obstructive } \\
\text { from non-obstructive azoospermia }\end{array}$ & $\begin{array}{l}\text { (Drabovich et al., 2013; Yamakawa } \\
\text { et al., 2007) }\end{array}$ \\
\hline & & $\begin{array}{l}\text { Higher expression of seminal LGALS3BP in men } \\
\text { with successful TESE }\end{array}$ & (Freour et al., 2013). \\
\hline Oligoasthenozoospermia & Seminal plasma & $\begin{array}{l}\text { Proposed markers to discriminate between } \\
\text { oligoasthenoteratozoospermic (OAT) and } \\
\text { normozoospermic patients: KLK3, LTF } \\
\text { SERPINA1, GAPDH, NPC2, M2BP and } \\
\text { lipocalin-1 }\end{array}$ & $\begin{array}{l}\text { (Giacomini et al., 2015; Liu, Wang, } \\
\text { et al., 2018) }\end{array}$ \\
\hline Globozoospermia & Spermatozoa & $\begin{array}{l}\text { Overexpression of AKAP4 and actin, as well as } \\
\text { the underexpression of enzymes of the Krebs } \\
\text { cycle, tubulin, and proteins associated with the } \\
\text { outer dense fibres and acrosome membrane }\end{array}$ & (Liao et al., 2009) \\
\hline
\end{tabular}

of new technologies facilitates the detection of maximum number of molecules (Wishart et al., 2013). Therefore, the investigation of a less number of molecules to be analysed makes metabolomics easier to be performed in a short period of time compared to other -OMICS approaches (Newgard, 2017). So far, the metabolomics studies were carried out using different human biological systems such as cells, tissues or fluids, including urine, blood plasma and serum, cerebrospinal fluid, saliva, follicular fluid, breast milk, tears and seminal plasma (Wishart et al., 2013; Zhang et al., 2012). Moreover, metabolomic studies have been conducted in several fields of human medicine such as pharmacology, toxicology, nutrition, cancer, metabolic diseases and reproduction (ČuperlovićCulf, Barnett, Culf, \& Chute, 2010; Vivanco et al., 2011; Zhang et al., 2012).

In general, heterogeneous nature of the metabolites makes it challenging to perform metabolomics experiments, whereas the 
heterogeneity of the molecules is comparatively less with other -OMICS approaches (Patti, Yanes, \& Siuzdak, 2012). This can be partially overcome by using more efficient metabolite extraction and separation procedures, high-throughput platforms to scan and detect a large number of metabolites, and computational tools for storage, processing and analysis of large data sets (Zhang et al., 2012). To analyse intracellular metabolites, cells are completely lysed to extract the metabolites. The protocol used to extract the metabolites can introduce variability due to the selectively loss of particular molecules, while alteration of the metabolic profile can be due to mistakes induced by the operator or long processing time (Patti et al., 2012). However, metabolomic profiling of body fluids does not require pre-processing steps, which in turn reduces the sample preparation time and technical bias. Once sample has been collected, the metabolic activities in the cell must be arrested in order to reliably reflect the metabolomic profile at the time of collection. This is achieved by freezing the sample in liquid nitrogen, which is stored at $-80^{\circ} \mathrm{C}$, and further extraction of metabolites (Gika, Theodoridis, \& Wilson, 2008). Most commonly employed separation techniques for metabolomic studies include high-performance liquid chromatography (HPLC) and capillary electrophoresis as well as gas chromatography (Fiehn, 2008; Juo, Chiu, \& Shiao, 2008). The qualitative and quantitative analysis of metabolites can be performed by several advanced techniques such MS, nuclear magnetic resonance (NMR) spectroscopy, near infrared (NIR) and Raman spectroscopy (Deepinder, Chowdary, \& Agarwal, 2007; Lindon \& Nicholson, 2008). The metabolite identification/detection capacity of these techniques is limited and can univocally identify metabolites from one-third of the approximately 10,000 spectra obtained. However, these advanced techniques can be used complementarily to detect maximum number of metabolites starting from a very low amount of sample (Patti et al., 2012; Zamboni, Saghatelian, \& Patti, 2015). Different databases such as HMDB, KEGG, PubChem, ChEBI, BioCyc/HumanCyc, LipidMAPS, ChemSpider, METLIN and Recon2 are used to identify the metabolites present in the given sample (Marco-Ramell et al., 2018). Analysis of the data can vary as fingerprinting, footprinting and profiling approaches based on the final goal (Vivanco et al., 2011). Metabolomic fingerprinting is a comparative analysis of metabolite profiles between two conditions rather than the identification of all metabolites present in the system. The footprinting aims to identify all the molecules which are released in the extracellular space, while metabolomics profiling analyses a pre-determined set of metabolites involved in specific pathways (Vivanco et al., 2011). In fact, the comparison with a placebo-treated system or a healthy control makes possible the investigation of metabolic pathways directly altered by the treatment/disease and the identification of more reliable molecular biomarkers of disease.

\section{7 | METABOLOMICS AND MALE REPRODUCTION}

In male reproduction, metabolomic studies have been conducted to shed light on the altered pathways in male infertility scenarios.
The results from investigation of metabolites in sperm cells, seminal plasma and testicular tissue are described in the next sections.

\section{1 | Sperm metabolomics}

Metabolomics analysis of the spermatozoa is challenging due to the presence of seminal plasma and use of reagents for sperm washing that potentially interfere with metabolomics analysis. The first metabolomics study on spermatozoa was conducted in 2015 by Paiva et al. using spermatozoa selected by density gradient. The metabolome of spermatozoa was analysed by combining results from proton nuclear magnetic resonance $\left({ }^{1} \mathrm{H}-\mathrm{NMR}\right)$ spectroscopy and gas chromatography-mass spectrometry (GC-MS) (Paiva et al., 2015), detecting a maximum number of metabolites $(n=69)$. For the first time, authors reported intracellular metabolome of the spermatozoa such as amino acids, peptides and analogues as the most representative molecules, followed by lipids organic acids, aliphatic acyclic compounds, carbohydrates and nucleotides. The presence of lactate, carnitine and acetylcarnitine in important metabolomic pathways such as glycolysis and fatty acid oxidation and its association with sperm physiology provided foundation for further studies. Two years later, Reynolds et al. used ${ }^{1} \mathrm{H}$-NMR to profile the metabolome of spermatozoa selected by density gradient. Metabolome profiles of mature and immature fraction of spermatozoa revealed differences in lipid composition with a higher concentration of lactate, choline and glycerophosphocholine in immature fraction due to the presence of morphological defects in the selected sperm population (Reynolds, Calvert, Paley, \& Pacey, 2017).

Metabolomic profile of spermatozoa investigated by GC-MS in idiopathic asthenozoospermic patients revealed the under- and overexpression of 27 and 6 metabolites, respectively, when compared to the healthy subjects (Zhao et al., 2018). Molecular pathways related to the metabolism of nucleosides, amino acids and sugars were altered in asthenozoospermic samples. Some essential amino acids, such as tryptophan and leucine, were significantly underexpressed, suggesting that sperm motility of asthenozoospermic patients can be improved by exogenous amino acid supplementation. Further, reduced levels of 3-phosphoglycerate and lactic acid suggested a disturbance in glycolysis and Krebs cycle pathways, with consequences on energy production. Targeted metabolomic experiments on semen before and after cryopreservation showed disturbance in sugar metabolism associated with reduced semen motility following freezing/thawing processes (Fu et al., 2019). Metabolomics analysis revealed dysfunction of glycolysis pathway in cryopreserved spermatozoa, also supported by the underexpression of the hexokinases (HK2) enzyme, detected by Western blotting. Finally, intracellular metabolic profile has been correlated with semen parameters by analysing semen samples from healthy volunteers (Engel et al., 2019). Specifically, alterations of the intracellular metabolites' concentration such as acylcarnitines, lysophosphatidylcholines, phosphatidylcholines, 
sphingomyelins and sugars have been closely associated with sperm motility. Although further studies are needed to identify the physiological concentration of such metabolites, these preliminary results laid the foundation for the identification of more reliable molecular markers of semen quality.

\section{2 | Seminal plasma metabolomics}

The first metabolomics study on seminal plasma was published by Hamamah et al. in 1993, and analysed metabolomics profile of seminal plasma in infertile patients with obstructive azoospermia, oligoasthenoteratozoospermia and spermatogenic failure (Hamamah et al., 1993) (Table 2). The results, obtained by ${ }^{1} \mathrm{H}-\mathrm{NMR}$, were compared to those from a control group of normozoospermic men. Hamamah et al suggested that a combination of biomarkers, such as glycerylphosphorylethanolamine-GPC, citrate and lactate, might be used to differentiate obstructive azoospermic patients, while the ratios between citrate:lactate and GPC:lactate were altered in both oligoasthenoteratozoospermic and spermatogenic failure patients (Hamamah et al., 1993). The other metabolites such as alanine, tyrosine and phenylalanine were also reported to be altered in infertile normozoospermic and oligozoospermic patients (Gupta et al., 2011). Xu et al. used LC-MS technique to identify the difference in seminal metabolome between fertile and infertile patients (Xu, Lu, Wang, Zhang, \& Wu, 2020). A total of 63 metabolites were identified as potential biomarkers of infertility, and 17 of these were correlated with semen parameters. The relationship was established between acylcarnitines and sperm concentration, sperm motility and antioxidant levels in semen. Furthermore, carnitines involved in the sperm maturation process (Niederberger, 2005) also has an impact on oxidative stress (Dobrakowski et al., 2017).

The metabolic seminal profile was also analysed in male infertility-associated conditions such as spinal cord injury and obesity by MALDI-TOF MS, and Kidney Young deficiency syndrome (KYDS) by LC/QTOF-MS (Chen, Hu, Dai, \& Chen, 2015; Guo et al., 2017; da Silva et al., 2011). In case of spinal cord injury, altered metabolites were associated with metabolism and biosynthesis of lipids, nucleotides, response to oxidative stress and vitamins (da Silva et al., 2011), whereas KIDS seminal plasma metabolome showed altered biosynthesis and metabolism of aromatic amino acids, sugars and lipids (Chen et al., 2015). Spermidine and spermine levels were increased in obese patients with abnormal semen quality, highlighting the role of these polyamines in the testicular development and spermatogenesis (Guo et al., 2017).

Metabolomics of seminal plasma was also investigated in several conditions related to sperm abnormalities. Jayaraman et al. used ${ }^{1} \mathrm{H}$-NMR to analyse seminal plasma metabolome of oligozoospermic, asthenozoospermic, teratozoospermic, azoospermic and idiopathic infertile men (Jayaraman et al., 2014). Besides the altered metabolites, a unique metabolic profile was identified in idiopathic infertility, characterised by altered levels of fructose, citrate and amino acids (lysine, arginine, tyrosine and proline). These metabolic dysfunctions in seminal plasma may explain the origin of idiopathic infertility (Jayaraman et al., 2014). Similarly in the case of UMI, amino acid catabolism was increased, which indicates that oxidative stress is associated with the UMI aetiology (Jafarzadeh et al., 2015; Qiao et al., 2017).

Since 2014, different techniques have been used to profile the metabolome of asthenozoospermic patients. By performing ${ }^{1} \mathrm{H}-\mathrm{NMR}$, metabolomic dysregulations related to sugars, lipids and amino acids were reported in seminal plasma of asthenozoospermic patients and indicate that oxidative stress mechanism is disturbed in asthenozoospermia (Jayaraman et al., 2014; Zhang, Diao, Zhu, Li, \& Cai, 2015). Moreover, GC-MS identified increased levels of oleic and palmitic acids and reduced valine concentration that may cause membrane dysfunction and poor sperm motility, respectively (Tang et al., 2017). Furthermore, HPLC-ESI-MS/MS techniques was able to report the alteration of metabolites related to arachidonic acid metabolism (arachidonic acid, 15-HETE, 8,9-EET, PGE 2 , 14,15-DHET, 14,15-EET, PGD 2 , 5-HETE, PGF ${ }_{2 \alpha}$, Tetranor-PGEM, 11,12-DHET, 20-HETE) (Yu et al., 2019), whereas metabolomic fingerprinting of seminal plasma assessed by Raman spectroscopy was able to discriminate asthenozoospermic from normozoospermic patients (Gilany, Moazeni-Pourasil, Jafarzadeh, \& Savadi-Shiraz, 2014)

Engel et al. reported that the metabolomic profile of seminal plasma correlated with the sperm concentration and morphology in healthy donors using LC-MS/MS approach (Engel et al., 2019). Huang et al. reported an association between sperm concentration/ sperm count and products of fatty acid, lipid and amino acid metabolism (Huang et al., 2019). Metabolomics platform was used to evaluate the relationship between the metabolites in seminal plasma and normal sperm morphology. Reduced levels of metabolites, such as amino acids, lactate, citrate, creatinine, $\alpha$-ketoglutaric acid, spermine and putrescine, were noticed in the seminal plasma of oligoasthenozoospermic patients (Mumcu, Karaer, Dogan, \& Tuncay, 2019). On the other hand, amino acids, citric acid, choline, D-glucose, myo-inositol, lactate and pyruvate were significantly overexpressed in infertile teratozoospermic patients (Mehrparvar et al., 2020). In oligozoospermic patients, ${ }^{1} \mathrm{H}-\mathrm{NMR}$ detected altered levels of fructose, myo-inositol, aspartate and choline, involved in the sperm maturation, energy metabolism and cell membrane composition (Murgia et al., 2020). Future in-depth studies are required to better investigate the seminal metabolome and identify biomarkers associated with sperm abnormalities.

Metabolomics has been recently applied to the field of assisted reproductive techniques (ART) to predict spermatogenesis in nonobstructive azoospermic (NOA) patients (Gilany et al., 2017, 2018). Techniques such as GS-MS and Raman spectroscopy were able to identify 36 discriminatory metabolites in seminal plasma as well as to classify NOA patients based on the TESE outcome. Although the field of metabolomics in male reproductive research is still in emerging phase, metabolites are very promising non-invasive biomarkers for the diagnosis and management of male infertility. 
TABLE 2 Metabolomics studies in seminal plasma

\begin{tabular}{|c|c|c|c|}
\hline References & Studied population & $\begin{array}{l}\text { Metabolomics } \\
\text { techniques }\end{array}$ & Main findings \\
\hline $\begin{array}{l}\text { Hamamah } \\
\text { et al. (1993) }\end{array}$ & $\begin{array}{l}\text { Spermatogenic failure (21) } \\
\text { OA (14) } \\
\text { OAT (7) } \\
\text { Normozoospermia (18) }\end{array}$ & ${ }^{1} \mathrm{H}-\mathrm{NMR}$ & $\begin{array}{l}\text { Glycerylphosphorylethanolamine, citrate and lactate } \\
\text { varied in azoospermic men, while citrate:lactate ratios and } \\
\text { GPC:lactate ratios were altered in spermatogenic failure } \\
\text { and OA }\end{array}$ \\
\hline Gupta et al. (2011) & $\begin{array}{l}\text { Infertile normozoospermic (65) } \\
\text { Infertile oligozoospermic (60) } \\
\text { Healthy fertile men (60) }\end{array}$ & ${ }^{1} \mathrm{H}-\mathrm{NMR}$ & $\begin{array}{l}\text { Alanine, citrate, glycerylphosphorylcholine, tyrosine and } \\
\text { phenylalanine suggested as biomarkers for screening of } \\
\text { male infertility }\end{array}$ \\
\hline $\begin{array}{l}\text { da Silva } \\
\text { et al. (2011) }\end{array}$ & $\begin{array}{l}\text { Spinal cord injury (6) } \\
\text { Healthy controls (6) }\end{array}$ & MALDI-TOF MS & $\begin{array}{l}\text { Altered pathways in spinal cord injury patients: biosynthesis } \\
\text { of nucleotides, sterol biosynthesis, arachidonic acid } \\
\text { metabolism and response to hydrogen peroxide, steroid } \\
\text { hormone and vitamins. }\end{array}$ \\
\hline $\begin{array}{l}\text { Jayaraman } \\
\text { et al. (2014) }\end{array}$ & $\begin{array}{l}\text { Idiopathic male infertility (17) } \\
\text { Oligozoospermia (20) } \\
\text { Asthenozoospermia (20) } \\
\text { Teratozoospermia (20) } \\
\text { Azoospermia (20) } \\
\text { Normozoospermia (6) }\end{array}$ & ${ }^{1} \mathrm{H}-\mathrm{NMR}$ & $\begin{array}{l}\text { Idiopathic infertile men profile differed from that of fertile } \\
\text { controls and other infertile groups due to either up- or } \\
\text { downregulation of lysine, fructose, arginine, tyrosine, } \\
\text { citrate and proline }\end{array}$ \\
\hline Gilany et al. (2014) & $\begin{array}{l}\text { Asthenozoospermia (13) } \\
\text { Normozoospermia (13) }\end{array}$ & $\begin{array}{l}\text { Raman } \\
\text { spectroscopy }\end{array}$ & $\begin{array}{l}\text { Metabolomic fingerprinting could be used to discriminate } \\
\text { between asthenozoospermic and normozoospermic males }\end{array}$ \\
\hline Zhang et al., 2015 & $\begin{array}{l}\text { Asthenozoospermia (33) } \\
\text { Healthy men (30) }\end{array}$ & ${ }^{1} \mathrm{H}-\mathrm{NMR}$ & $\begin{array}{l}\text { Asthenozoospermia associated with metabolic dysregulation } \\
\text { of amino acids, lipids, phospholipids (choline), cholesterol, } \\
\text { nucleosides, sugar and energy generation. } \\
\text { Overexpression of oxysterols indicated the role of oxidative } \\
\text { stress in the mechanism of asthenozoospermia. }\end{array}$ \\
\hline Chen et al. (2015) & $\begin{array}{l}\text { Infertile males with Kidney } \\
\text { Yang Deficiency Syndrome } \\
\text { (KYDS) (18) } \\
\text { Fertile men (18) }\end{array}$ & LC/QTOF-MS & $\begin{array}{l}\text { Changes in metabolic pathways of biosynthesis and } \\
\text { metabolism of aromatic amino acids, citric acid cycle } \\
\text { and sphingolipid metabolism may contribute to the } \\
\text { development of KYDS-associated infertility }\end{array}$ \\
\hline Qiao et al. (2017) & $\begin{array}{l}\text { UMI (80) } \\
\text { Fertile men (80) }\end{array}$ & $\mathrm{GC} / \mathrm{MS}$ & $\begin{array}{l}\text { Increased catabolism of various amino acids. } \\
\text { 4-Hydroxyphenylacetic acid is a key metabolite in } \\
\text { differentiating between UMI and controls, and its seminal } \\
\text { plasma concentration related positively to sperm counts }\end{array}$ \\
\hline Guo et al. (2017) & $\begin{array}{l}\text { Normal BMI, normal semen } \\
\text { quality (55) } \\
\text { Obese, abnormal semen quality } \\
\text { (9) }\end{array}$ & MALDI-TOF MS & $\begin{array}{l}\text { Spermidine and spermine significantly higher in obese men } \\
\text { with abnormal semen quality. They were likely to play a } \\
\text { vital role in the spermatogenesis progress. }\end{array}$ \\
\hline Gilany et al. (2017) & $\begin{array}{l}\text { NOA with TESE-negative (11) } \\
\text { NOA with TESE-positive (9) } \\
\text { Fertile healthy men (10) }\end{array}$ & GS-MS & $\begin{array}{l}36 \text { discriminatory metabolites for different groups in NOA } \\
\text { condition }\end{array}$ \\
\hline Gilany et al. (2018) & $\begin{array}{l}\text { NOA with TESE-negative (10) } \\
\text { NOA with TESE-positive (10) } \\
\text { Fertile healthy men (15) }\end{array}$ & $\begin{array}{l}\text { Raman } \\
\text { spectroscopy }\end{array}$ & $\begin{array}{l}\text { The seminal plasma metabolome could be used to detect } \\
\text { spermatogenesis in NOA patients. } \\
\text { TESE-negative patients have severe oxidative imbalance } \\
\text { compared to TESE-positive }\end{array}$ \\
\hline (Yu et al., 2019) & $\begin{array}{l}\text { Asthenozoospermia (30) } \\
\text { Healthy men (33) }\end{array}$ & HPLC-ESI-MS/MS & $\begin{array}{l}\text { A significant disorder of arachidonic acid metabolism was } \\
\text { observed in asthenozoospermic samples. }\end{array}$ \\
\hline Engel et al. (2019) & Healthy donors (20) & LC-MS/MS & $\begin{array}{l}\text { Seminal plasma metabolites are closely related to sperm } \\
\text { concentration and morphology }\end{array}$ \\
\hline
\end{tabular}


TABLE 2 (Continued)

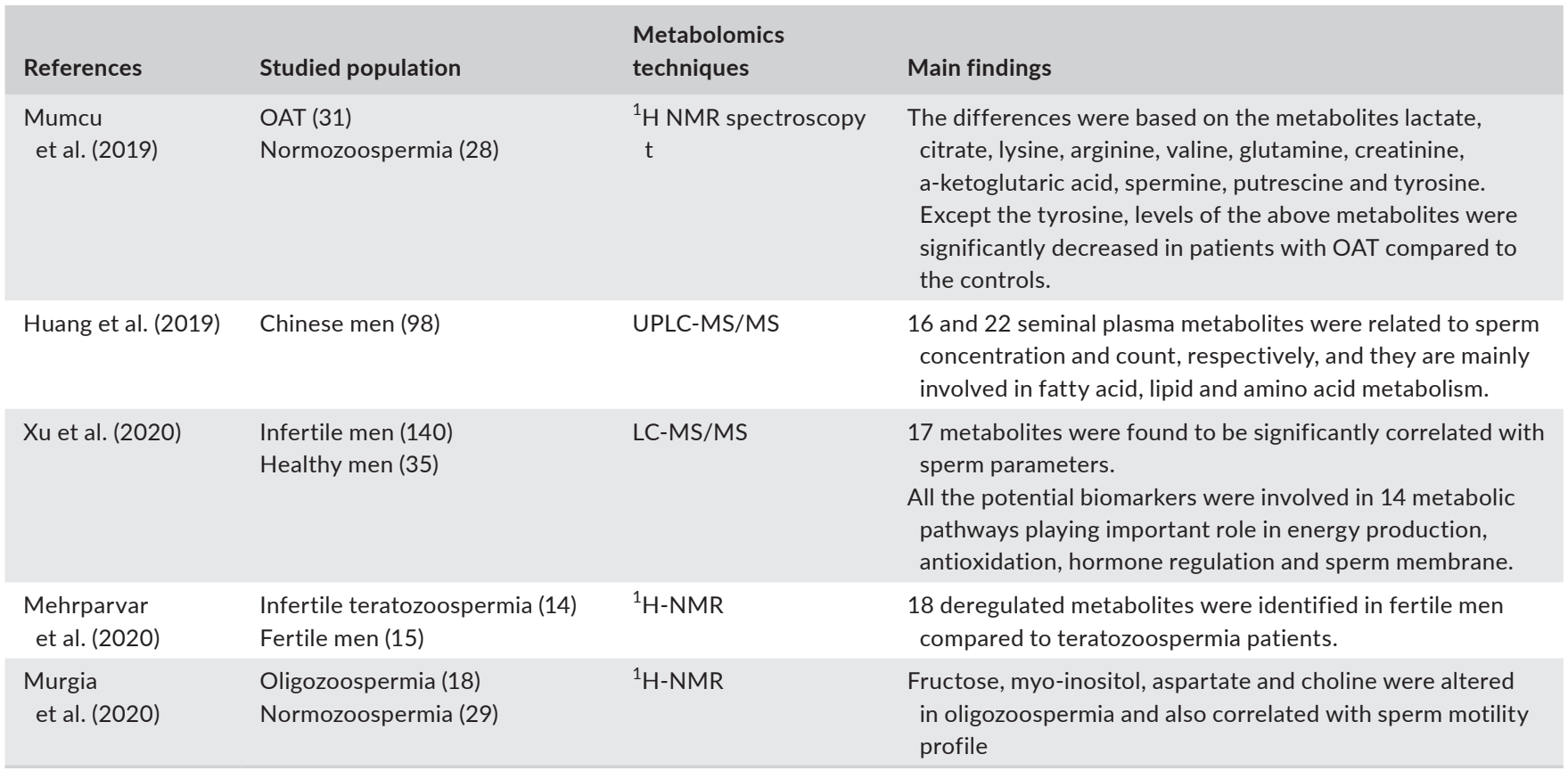

Abbreviations: BMI, body mass index; NOA, non-obstructive azoospermia; OA, obstructive azoospermia; OAT, oligoasthenoteratozoospermia; TESE, testicular sperm extraction.

\section{3 | Testicular metabolomics}

Metabolomics has been used as a non-invasive tool to investigate the occurrence of spermatogenesis in the testicular tissue of non-obstructive azoospermic patients (Aaronson, Iman, Walsh, Kurhanewicz, \& Turek, 2010; Liu et al., 2014). Analysis of frozen testicular tissue with ${ }^{1} \mathrm{H}$-NMR revealed increased phosphocholine (PC) in patients with normal spermatogenesis undergoing vasectomy, in comparison with patients showing maturation arrest or Sertoli cell only syndrome (Aaronson et al., 2010). Hence, PC can be used as a putative screening biomarker of spermatogenesis, as its concentration is indicative of cellular proliferation and membrane synthesis (Aaronson et al., 2010). Liu et al., (2014) identified 12 differentially expressed metabolites using GS-MS in fresh seminiferous tubules of non-obstructive and obstructive azoospermic patients, with increased levels of cis-Phytol and glutamine, and decreased levels of saccharides and amino acids in non-obstructive testes. Further, Raman spectroscopy was able to distinguish the non-obstructive and obstructive azoospermic patients with high sensitivity (90\%) and specificity (85.71\%), emerging as a potential non-invasive tool to predict spermatogenesis in the seminiferous tubules (Liu et al., 2014).

\section{8 | METABOLOMICS IN PROGNOSIS AND DIAGNOSIS OF MALE INFERTILITY}

The identification of biomarkers for prognosis, diagnosis and severity, as well as to predict the success of a therapeutic approach, is one of the main goal of metabolomics studies. An ideal biomarker should have high sensitivity and specificity, and its detection should be easy and noninvasive as well as fast and economically sustainable (Bieniek, Drabovich, \& Lo, 2016). Moreover, using a combination or panel of biomarkers may increase their power as a prognostic and diagnostic tool. Metabolites present in the seminal plasma can serve as predictive biomarkers in several conditions associated with male infertility (Table 3). A group of metabolites (alanine, citrate, GPC, tyrosine and phenylalanine) was able to discriminate patients based on the fertility status as well as oligozoospermic from normozoospermic patients with the accuracy of $92.4 \%$ and $92.9 \%$, respectively (Gupta et al., 2011). Lysine was proposed as a potential biomarker to discriminate idiopathic infertile men from normozoospermic men (Jayaraman et al., 2014). Qiao et al. developed a model based on 153 differentially expressed metabolites in seminal plasma to discriminate UMI patients from fertile healthy men with a specificity of $92 \%$ (Qiao et al., 2017). Particularly, 4-hydroxyphenylacetic acid positively correlated with the sperm count and considered as decisive in screening UMI patients. A group of metabolites composed by lactate, citrate, lysine, arginine, valine, glutamine, creatinine, $\alpha$-ketoglutaric acid, spermine, putrescine and tyrosine was also recommended to discriminate normozoospermic and oligoasthenoteratozoospermic samples (Mumcu et al., 2019), while altered levels of aspartate, choline, fructose and myo-inositol were reported in oligozoospermic cases (Murgia et al., 2020). Metabolomics study conducted on sperm cells isolated by density gradient centrifugation suggested that 33 altered metabolites may be used as a molecular signature of idiopathic asthenozoospermia (Zhao et al., 2018). Metabolites concentration in blood and urine samples is used to predict the fertility status of men. Combination of urinary metabolites was used to predict the sperm abnormalities. Carnitines and aspartic acid were 
able to predict oligozoospermia with moderate sensitivity (65\%) and specificity (71\%) (Zhang et al., 2014). Idiopathic normozoospermic infertile men can be predicted using a combination of 5 biomarkers (leukotriene E4, carnitine, aspartate, xanthosine and methoxytryptophan) (Zhang et al., 2014). In fact, higher sensitivity (85.7\%) and specificity $(86.8 \%)$ were noticed when they were all included in the predictive model in comparison with using the single markers. Like urine and seminal plasma, blood metabolites are analyzed and used as a non-invasive tool for differential disease diagnosis. A recent multivariate analysis identified a set of 38 metabolites from blood plasma to discriminate healthy controls from infertile men with semen abnormalities (sensitivity: $78.69 \%$, specificity: $84.09 \%$ ) and infertile men with erectile dysfunction (sensitivity: $80.33 \%$, specificity: 100\%) (Zhou et al., 2016). Metabolomics is emerging as a new promising tool for the diagnosis and prognosis of male infertility, and its application to the semen and other biological fluids will provide evidence on the metabolic dysfunctions associated with the male infertility.

\section{9 | CHALLENGES AND FUTURE PERSPECTIVES OF PROTEOMICS AND METABOLOMICS IN CLINICAL ANDROLOGY}

Adjunct use of biomarker screening along with standard semen analysis may increase the diagnostic power in evaluating the male

TABLE 3 Studies showing the diagnostic/prognostic power of metabolomics

\begin{tabular}{|c|c|c|c|}
\hline References & Sample/ Studied population & Metabolomics techniques & Main findings \\
\hline Gupta et al. (2011) & $\begin{array}{l}\text { Seminal plasma } \\
\text { Infertile normozoospermic } \\
\text { (65) } \\
\text { Infertile oligozoospermic } \\
\text { (60) Healthy fertile men } \\
\text { (60) }\end{array}$ & ${ }^{1} \mathrm{H}-\mathrm{NMR}$ & $\begin{array}{l}\text { Alanine, citrate, GPC, tyrosine and phenylalanine } \\
\text { can be used to determine infertility. } \\
\text { High accuracy in differentiating healthy } \\
\text { controls from infertile patients }(92.4 \%) \text { and } \\
\text { normozoospermic from oligozoospermic } \\
\text { samples }(92.9 \%)\end{array}$ \\
\hline Jayaraman et al. (2014) & $\begin{array}{l}\text { Seminal plasma } \\
\text { Idiopathic male infertility } \\
\text { (17) } \\
\text { Oligozoospermia (20) } \\
\text { Asthenozoospermia (20) } \\
\text { Teratozoospermia (20) } \\
\text { Azoospermia (20) } \\
\text { Normozoospermia (6) }\end{array}$ & ${ }^{1} \mathrm{H}-\mathrm{NMR}$ & $\begin{array}{l}\text { Lysine has the potential to aid in the detection } \\
\text { and diagnosis of idiopathic infertility }\end{array}$ \\
\hline Zhang et al. (2014) & $\begin{array}{l}\text { Urine } \\
\text { Normozoospermic infertile } \\
\text { cases }(n=71) \text { and fertile } \\
\text { controls }(n=47)\end{array}$ & $\begin{array}{l}\text { LC/ } \\
\text { MicrOTOF-Q II } \\
\text { MS }\end{array}$ & $\begin{array}{l}\text { Leukotriene E4, 3-hydroxypalmitoylcarni- tine, } \\
\text { aspartate, xanthosine and methoxytryptophan } \\
\text { can discriminate normozoospermic infertile } \\
\text { patients from fertile controls }\end{array}$ \\
\hline Zhang et al. (2014) & $\begin{array}{l}\text { Urine } \\
\text { Oligozoospermic infertile } \\
\text { men (135) } \\
\text { Fertile volunteers (158) }\end{array}$ & LC/QTOF-MS & $\begin{array}{l}\text { The combined pattern of acetylcarnitine, } \\
\text { carnitine C } 3: 1 \text { and aspartic acid provided } \\
\text { moderate diagnostic power for oligozoospermic } \\
\text { infertility }\end{array}$ \\
\hline Zhou et al. (2016) & $\begin{array}{l}\text { Blood sample } \\
\text { Erectile dysfunction (26) } \\
\text { Semen abnormalities (44) } \\
\text { Healthy controls (61) }\end{array}$ & GC-MS & $\begin{array}{l}\text { Set of metabolites from plasma samples was } \\
\text { proposed to discriminate healthy controls from } \\
\text { infertile men with semen abnormalities and } \\
\text { infertile men with erectile dysfunction }\end{array}$ \\
\hline Qiao et al. (2017) & $\begin{array}{l}\text { Seminal plasma } \\
\text { UMI (80) } \\
\text { Fertile men (80) }\end{array}$ & GC/MS & $\begin{array}{l}153 \text { seminal plasmatic metabolites were able } \\
\text { to distinguish } 82 \% \text { of the UMI patients from } \\
\text { healthy controls with a specificity of } 92 \%\end{array}$ \\
\hline Zhao et al. (2018) & $\begin{array}{l}\text { Spermatozoa } \\
\text { Idiopathic } \\
\text { asthenozoospermia (30) } \\
\text { Healthy subjects (30) }\end{array}$ & GC-MS & $\begin{array}{l}\text { Altered expression of metabolites was } \\
\text { used to discriminate between idiopathic } \\
\text { asthenozoospermic patients and healthy } \\
\text { controls }\end{array}$ \\
\hline Mumcu et al. (2019) & $\begin{array}{l}\text { Seminal plasma } \\
\text { OAT (31) } \\
\text { Normozoospermia (28) }\end{array}$ & ${ }^{1} \mathrm{H}$ NMR spectroscopy $\mathrm{t}$ & $\begin{array}{l}\text { A PLS-DA model built on the NMR data achieved } \\
89.29 \% \text { sensitivity and } 93.55 \% \text { specificity } \\
\text { results in a leave-one-out cross-validation } \\
\text { process }\end{array}$ \\
\hline Murgia et al. (2020) & $\begin{array}{l}\text { Seminal plasma } \\
\text { Oligozoospermia (18) } \\
\text { Normozoospermia (29) }\end{array}$ & ${ }^{1} \mathrm{H}-\mathrm{NMR}$ & $\begin{array}{l}\text { NMR-based metabolomics allowed the } \\
\text { identification of a specific metabolic fingerprint } \\
\text { of the seminal fluids of patients affected by } \\
\text { oligozoospermia }\end{array}$ \\
\hline
\end{tabular}


infertility, particularly in case of idiopathic male infertility (Jungwirth et al., 2016). Male infertility is a multifactorial disorder and the use of a set of biomarkers instead of a single biomarker may significantly enhance the predictive power of pathological conditions (Zhang et al., 2014). Longo et al. (2018) reported that volatile metabolites (volatilome) were able to demonstrate a relationship between sperm metabolism and male infertility in astheno- and oligozoospermic patients. The identification of altered metabolic processes in male infertility scenarios by proteomics and metabolomics studies will open the avenue for the identification of novel therapeutic targets. Further studies based on larger and heterogeneous population are required to validate the preliminary markers identified in the clinical practice. The presence of confounding factors, such as age, gender, nationality, exposure to environmental factors, should be taken into consideration during the analysis.

\section{0 | CONCLUSION}

Proteomics and metabolomics are emerging as powerful tools to investigate the molecular causes of male infertility. The application of high-throughput platforms for the detection of proteins and metabolites, combined with the use of sophisticated bioinformatic software for their analysis, will enable the identification of biomarkers for prognosis and diagnosis of male infertility and prediction of reproductive outcomes in the ART. The understanding of the molecular changes associated with male infertility will help in planning ad hoc treatments, with significant contribution in the clinical management of infertile patients.

\section{1 | TAKE HOME MESSAGE}

- Proteomics and metabolomics can decipher the molecular etiologies associated with male infertility conditions.

- Proteomics and metabolomics may allow the identification of more reliable markers of diagnosis and prognosis of male infertility.

\section{ORCID}

Manesh Kumar Panner Selvam (iD https://orcid.

org/0000-0002-9120-2278

Renata Finelli (iD https://orcid.org/0000-0002-5926-6407

Ashok Agarwal iD https://orcid.org/0000-0003-0585-1026

Ralf Henkel iD https://orcid.org/0000-0003-1128-2982

\section{REFERENCES}

Aaronson, D. S., Iman, R., Walsh, T. J., Kurhanewicz, J., \& Turek, P. J. (2010). A novel application of $1 \mathrm{H}$ magnetic resonance spectroscopy: Non-invasive identification of spermatogenesis in men with non-obstructive azoospermia. Human Reproduction, 25(4), 847-852. https:// doi.org/10.1093/humrep/dep475

Adra, N., \& Einhorn, L. H. (2017). Testicular cancer update. Clinical Advances in Hematology and Oncology, 15(5), 386-396.
Agarwal, A., Baskaran, S., Panner Selvam, M. K., Barbarosie, C., \& Master, K. (2020). Unraveling the footsteps of proteomics in male reproductive research: A scientometric approach. Antioxidants and Redox Signaling, 32(8), 536-549. https://doi.org/10.1089/ars.2019.7945

Agarwal, A., Panner Selvam, M. K., Samanta, L., Vij, S. C., Parekh, N., Sabanegh, E., Sharma, R. (2019). Effect of antioxidant supplementation on the sperm proteome of idiopathic infertile men. Antioxidants, $8(10), 488$

Agarwal, A., Sharma, R., Durairajanayagam, D., Ayaz, A., Cui, Z., Willard, B., Sabanegh, E. (2015). Major protein alterations in spermatozoa from infertile men with unilateral varicocele. Reproductive Biology and Endocrinology, 13(8).1-22.

Agarwal, A., Sharma, R., Durairajanayagam, D., Cui, Z., Ayaz, A., Gupta, S., ... Sabanegh, E. (2015). Differential proteomic profiling of spermatozoal proteins of infertile men with unilateral or bilateral varicocele. Urology, 85(3), 580-588. https://doi.org/10.1016/j.urolo gy.2014.11.030

Agarwal, A., Sharma, R., Harlev, A., \& Esteves, S. C. (2016). Effect of varicocele on semen characteristics according to the new 2010 World Health Organization criteria: A systematic review and meta-analysis. Asian Journal of Andrology, 18(2), 163-170. https://doi. org/10.4103/1008-682X.172638

Agarwal, A., Sharma, R., Samanta, L., Durairajanayagam, D., \& Sabanegh, E. (2016). Proteomic signatures of infertile men with clinical varicocele and their validation studies reveal mitochondrial dysfunction leading to infertility. Asian Journal of Andrology, 18(2), 282-291. https://doi.org/10.4103/1008-682X.170445

Agarwal, A., Tvrda, E., Sharma, R., Gupta, S., Ahmad, G., \& Sabanegh, E. S. (2015). Spermatozoa protein profiles in cryobanked semen samples from testicular cancer patients before treatment. Fertility and Sterility, 104(3), e260. https://doi.org/10.1016/j.fertnstert.2015.07.817

Aktan, G., Doğru-Abbasoğlu, S., Küçükgergin, C., Kadioğlu, A., Özdemirler-Erata, G., Koçak-Toker, N., ... Kocak-Toker, N. (2013). Mystery of idiopathic male infertility: Is oxidative stress an actual risk? Fertility and Sterility, 99(5), 1211-1215. https://doi. org/10.1016/j.fertnstert.2012.11.045

Alikhani, M., Mirzaei, M., Sabbaghian, M., Parsamatin, P., Karamzadeh, R., Adib, S., ... Salekdeh, G. H. (2017). Quantitative proteomic analysis of human testis reveals system-wide molecular and cellular pathways associated with non-obstructive azoospermia. Journal of Proteomics, 162, 141-154. https://doi.org/10.1016/j. jprot.2017.02.007

Alvarez Sedo', C., Rawe, V. Y., \& Chemes, H. E. (2012). Acrosomal biogenesis in human globozoospermia: Immunocytochemical, ultrastructural and proteomic studies. Human Reproduction, 27(7), 1912-1921. https://doi.org/10.1093/humrep/des126

Amaral, A., Castillo, J., Estanyol, J. M., Ballesca, J. L., Ramalho-Santos, J., \& Oliva, R. (2013). Human sperm tail proteome suggests new endogenous metabolic pathways. Molecular and Cellular Proteomics, 12(2), 330-342. https://doi.org/10.1074/mcp.M112.020552

Amaral, A., Castillo, J., Ramalho-Santos, J., \& Oliva, R. (2014). The combined human sperm proteome: Cellular pathways and implications for basic and clinical science. Human Reproduction Update, 20(1), 40-62. https://doi.org/10.1093/humupd/dmt046

Amaral, A., Paiva, C., Attardo Parrinello, C., Estanyol, J. M., Ballescà, J. L., Ramalho-Santos, J., \& Oliva, R. (2014). Identification of proteins involved in human sperm motility using high-throughput differential proteomics. Journal of Proteome Research, 13(12), 5670-5684. https://doi.org/10.1021/pr500652y

Ayaz, A., Agarwal, A., Sharma, R., Arafa, M., Elbardisi, H., \& Cui, Z. (2015). Impact of precise modulation of reactive oxygen species levels on spermatozoa proteins in infertile men. Clinical Proteomics, 12(1), 116. https://doi.org/10.1186/1559-0275-12-4

Azpiazu, R., Amaral, A., Castillo, J., Estanyol, J. M., Guimerà, M., Ballescà, J. L., ... Oliva, R. (2014). High-throughput sperm differential 
proteomics suggests that epigenetic alterations contribute to failed assisted reproduction. Human Reproduction, 29(6), 1225-1237. https://doi.org/10.1093/humrep/deu073

Baker, M. A., Naumovski, N., Hetherington, L., Weinberg, A., Velkov, T., \& Aitken, R. J. (2013). Head and flagella subcompartmental proteomic analysis of human spermatozoa. Proteomics, 13(1), 61-74. https://doi. org/10.1002/pmic.201200350

Baker, M. A., Witherdin, R., Hetherington, L., Cunningham-Smith, K., \& Aitken, R. J. (2005). Identification of post-translational modifications that occur during sperm maturation using difference in two-dimensional gel electrophoresis. Proteomics, 5(4), 1003-1012. https://doi. org/10.1002/pmic.200401100

Balk, S. P., Ko, Y. J., \& Bubley, G. J. (2003). Biology of prostate-specific antigen. Journal of Clinical Oncology, 21(2), 383-391. https://doi. org/10.1200/JCO.2003.02.083

Baskaran, S., Agarwal, A., Leisegang, K., Pushparaj, P. N., Panner Selvam, M. K., \& Henkel, R. (2019). An in-depth bibliometric analysis and current perspective on male infertility research. The World Journal of Men's Health, 37, 1-13. https://doi.org/10.5534/wjmh.180114

Belardin, L. B., Del Giudice, P. T., Camargo, M., Intasqui, P., Antoniassi, M. P., Bertolla, R. P., \& Cedenho, A. P. (2016). Alterations in the proliferative/apoptotic equilibrium in semen of adolescents with varicocele. Journal of Assisted Reproduction and Genetics, 33(12), 1657-1664. https://doi.org/10.1007/s10815-016-0808-z

Bieniek, J. M., Drabovich, A. P., \& Lo, K. C. (2016). Seminal biomarkers for the evaluation of male infertility. Asian Journal of Andrology, 18(3), 426-433. https://doi.org/10.4103/1008-682x.175781

Bogle, O. A., Kumar, K., Attardo-Parrinello, C., Lewis, S. E. M., Estanyol, J. M., Ballescà, J. L., \& Oliva, R. (2017). Identification of protein changes in human spermatozoa throughout the cryopreservation process. Andrology, 5(1), 10-22. https://doi.org/10.1111/andr.12279

Bracewell-Milnes, T., Saso, S., Abdalla, H., Nikolau, D., Norman-Taylor, J., Johnson, M., ... Thum, M. Y. (2017). Metabolomics as a tool to identify biomarkers to predict and improve outcomes in reproductive medicine: A systematic review. Human Reproduction Update, 23(6), 723-736. https://doi.org/10.1093/humupd/dmx023

Bracke, A., Peeters, K., Punjabi, U., Hoogewijs, D., \& Dewilde, S. (2018). A search for molecular mechanisms underlying male idiopathic infertility. Reproductive BioMedicine Online, 36(3), 327-339. https://doi. org/10.1016/j.rbmo.2017.12.005

Camargo, M., Intasqui, P., \& Pimenta Bertolla, R. (2016). Proteomic profile of seminal plasma in adolescents and adults with treated and untreated varicocele. Asian Journal of Andrology, 18(2), 194-201. https://doi.org/10.4103/1008-682X.168788

Camargo, M., Lopes, P. I., Del Giudice, P. T., Carvalho, V. M., Cardozo, K. H. M., Andreoni, C., ... Bertolla, R. P. (2013). Unbiased label-free quantitative proteomic profiling and enriched proteomic pathways in seminal plasma of adult men before and after varicocelectomy. Human Reproduction, 28(1), 33-46. https://doi.org/10.1093/humre $\mathrm{p} / \mathrm{des} 357$

Cao, X., Cui, Y., Zhang, X., Lou, J., Zhou, J., Bei, H., \& Wei, R. (2018). Proteomic profile of human spermatozoa in healthy and asthenozoospermic individuals. Reproductive Biology and Endocrinology, 16(1), 1-8. https://doi.org/10.1186/s12958-018-0334-1

Castillo, J., Knol, J. C., Korver, C. M., Piersma, S. R., Pham, T. V., de Goeij-de Haas, R. R., ... Jansen, B. J. H. (2019). Human testis phosphoproteome reveals kinases as potential targets in spermatogenesis and testicular cancer. Molecular and Cellular Proteomics, 18(Suppl 1), S132-S144. https://doi.org/10.1074/mcp.RA118.001278

Chan, C. C., Shui, H. A., Wu, C. H., Wang, C. Y., Sun, G. H., Chen, H. M., \& Wu, G. J. (2009). Motility and protein phosphorylation in healthy and asthenozoospermic sperm. Journal of Proteome Research, 8(11), 5382-5386. https://doi.org/10.1021/pr9003932

Chen, X., Hu, C., Dai, J., \& Chen, L. (2015). Metabolomics analysis of seminal plasma in infertile males with kidney-yang deficiency: A preliminary study. Evidence-Based Complementary and Alternative Medicine, 2015, 1-8. https://doi.org/10.1155/2015/892930

Chia, V. M., Quraishi, S. M., Devesa, S. S., Purdue, M. P., Cook, M. B., \& McGlynn, K. A. (2010). International trends in the incidence of testicular cancer, 1973-2002. Cancer Epidemiology Biomarkers and Prevention, 19(5), 1151-1159. https://doi.org/10.1158/1055-9965. EPI-10-0031

Chiriva-Internati, M., Gagliano, N., Donetti, E., Costa, F., Grizzi, F., Franceschini, B., Martin, W. M. (2009). Sperm protein 17 is expressed in the sperm fibrous sheath. Journal of Translational Medicine, 7(1), 1-5. https://doi.org/10.1186/1479-5876-7-61

Cohen, D. J., Maldera, J. A., Muñoz, M. W., Ernesto, J. I., Vasen, G., \& Cuasnicul, P. S. (2011). Cysteine-rich secretory proteins (CRISP) and their role in mammalian fertilization. Biological Research, 44(2), 135138. https://doi.org/10.4067/S0716-97602011000200004

Cui, Z., Sharma, R., \& Agarwal, A. (2016). Proteomic analysis of mature and immature ejaculated spermatozoa from fertile men. Asian Journal of Andrology, 18, 735-746. https://doi. org/10.4103/1008-682X.164924

Čuperlović-Culf, M., Barnett, D. A., Culf, A. S., \& Chute, I. (2010). Cell culture metabolomics: Applications and future directions. Drug Discovery Today, 15(15-16), 610-621. https://doi.org/10.1016/j. drudis.2010.06.012

da Silva, B. F., Del Giudice, P. T., Spaine, D. M., Gozzo, F. C., Lo Turco, E. G., \& Bertolla, R. P. (2011). Metabolomics of male infertility: Characterization of seminal plasma lipid fingerprints in men with spinal cord injury. Fertility and Sterility, 96(3), S233. https://doi. org/10.1016/j.fertnstert.2011.07.893

de Mateo, S., Castillo, J., Estanyol, J. M., Ballescà, J. L., \& Oliva, R. (2011). Proteomic characterization of the human sperm nucleus. Proteomics, 11(13), 2714-2726. https://doi.org/10.1002/pmic.201000799

Deepinder, F., Chowdary, H. T., \& Agarwal, A. (2007). Role of metabolomic analysis of biomarkers in the management of male infertility. Expert Review of Molecular Diagnostics, 7(4), 351-358. https://doi. org/10.1586/14737159.7.4.351

Del Giudice, P. T., Da Silva, B. F., Lo Turco, E. G., Fraietta, R., Spaine, D. M., Santos, L. F. A., ... Bertolla, R. P. (2013). Changes in the seminal plasma proteome of adolescents before and after varicocelectomy. Fertility and Sterility, 100(3), 667-672. https://doi.org/10.1016/j. fertnstert.2013.04.036

Deng, S., Jing, B., Xing, T., Hou, L., \& Yang, Z. (2012). Overexpression of annexin $A 2$ is associated with abnormal ubiquitination in breast cancer. Genomics, Proteomics and Bioinformatics, 10(3), 153-157. https:// doi.org/10.1016/j.gpb.2011.12.001

Dias, T. R., Agarwal, A., Pushparaj, P. N., Ahmad, G., \& Sharma, R. (2018). New insights on the mechanisms affecting fertility in men with non-seminoma testicular cancer before cancer therapy. The World Journal of Men's Health, 36.

Dias, T. R., Samanta, L., Agarwal, A., Pushparaj, P. N., Panner Selvam, M. K., \& Sharma, R. (2019). Proteomic signatures reveal differences in stress response, antioxidant defense and proteasomal activity in fertile men with high seminal ROS levels. International Journal of Molecular Sciences, 20(1). 203. https://doi.org/10.3390/ijms20010203

Dobrakowski, M., Kasperczyk, S., Horak, S., Chyra-Jach, D., Birkner, E., \& Kasperczyk, A. (2017). Oxidative stress and motility impairment in the semen of fertile males. Andrologia, 49(10), e12783. https://doi. org/10.1111/and.12783

Domagala, A., Pulido, S., Kamieniczna, M., Kurpisz, M., \& Herr, J. C.. (2011). An isoimmune response to human sperm clathrin in an infertile woman with systemic lupus erythematosus. Journal of Reproductive Immunology, 89(1), 95-102. https://doi.org/10.1016/j. jri.2011.01.015

Drabovich, A. P., Dimitromanolakis, A., Saraon, P., Soosaipillai, A., Batruch, I., Mullen, B., Diamandis, E. P. (2013). Differential diagnosis of azoospermia with proteomic biomarkers ECM1 and TEX101 
quantified in seminal plasma. Science Translational Medicine, 5(212), 212ra160. https://doi.org/10.1126/scitransImed.3006260

du Plessis, S. S., Kashou, A. H., Benjamin, D. J., Yadav, S. P., \& Agarwal, A. (2011). Proteomics: A subcellular look at spermatozoa. Reproductive Biology and Endocrinology, 9(36), 1-12. https://doi. org/10.1186/1477-7827-9-36

Elgün, S., Kaçmaz, M., Sen, I., \& Durak, I. (2000). Seminal arginase activity in infertility. Urological Research, 28(1), 20-23. https://doi. org/10.1007/s002400050004

Engel, K. M., Baumann, S., Rolle-Kampczyk, U., Schiller, J., von Bergen, M., \& Grunewald, S. (2019). Metabolomic profiling reveals correlations between spermiogram parameters and the metabolites present in human spermatozoa and seminal plasma. PLoS One, 14(2), 1-27. https://doi.org/10.1371/journal.pone.0211679

Fariello, R. M., Pariz, J. R., Spaine, D. M., Gozzo, F. C., Pilau, E. J., Fraietta, R., ... Cedenho, A. P. (2012). Effect of smoking on the functional aspects of sperm and seminal plasma protein profiles in patients with varicocele. Human Reproduction, 27(11), 3140-3149. https://doi. org/10.1093/humrep/des287

Ficarro, S., Chertihin, O., Westbrook, V. A., White, F., Jayes, F., Kalab, P., ... Visconti, P. E. (2003). Phosphoproteome analysis of capacitated human sperm: Evidence of tyrosine phosphorylation of a kinase-anchoring protein 3 and valosin-containing protein/p97 during capacitation. Journal of Biological Chemistry, 278(13), 11579-11589. https:// doi.org/10.1074/jbc.M202325200

Fiehn, O. (2008). Extending the breadth of metabolite profiling by gas chromatography coupled to mass spectrometry. Trends in Analytical Chemistry, 27(3), 261-269. https://doi.org/10.1016/j. trac.2008.01.007

Freour, T., Com, E., Barriere, P., Bouchot, O., Jean, M., Masson, D., \& Pineau, C. (2013). Comparative proteomic analysis coupled with conventional protein assay as a strategy to identify predictors of successful testicular sperm extraction in patients with non-obstructive azoospermia. Andrology, 1(3), 414-420. https://doi. org/10.1111/j.2047-2927.2012.00059.x

Fu, L., Liu, Y., An, Q., Zhang, J., Tong, Y., Zhou, F., \& Lu, W. (2019). Glycolysis metabolic changes in sperm cryopreservation based on a targeted metabolomic strategy. Int J Clin Exp Pathol, 12(5), 1775-1781.

Giacomini, E., Ura, B., Giolo, E., Luppi, S., Martinelli, M., Garcia, R. C., \& Ricci, G. (2015). Comparative analysis of the seminal plasma proteomes of oligoasthenozoospermic and normozoospermic men. Reproductive BioMedicine Online, 30(5), 522-531. https://doi. org/10.1016/j.rbmo.2015.01.010

Gika, H. G., Theodoridis, G. A., \& Wilson, I. D. (2008). Liquid chromatography and ultra-performance liquid chromatography-mass spectrometry fingerprinting of human urine. Sample stability under different handling and storage conditions for metabonomics studies. Journal of Chromatography A, 1189(1-2), 314-322. https://doi.org/10.1016/j. chroma.2007.10.066

Gilany, K., Jafarzadeh, N., Mani-Varnosfaderani, A., Minai-Tehrani, A., Sadeghi, M. R., Darbandi, M., ... Pahlevanzadeh, Z. (2018). Metabolic fingerprinting of seminal plasma from non-obstructive azoospermia patients: Positive versus negative sperm retrieval. Journal of Reproduction and Infertility, 19(2), 109-114.

Gilany, K., Mani-Varnosfaderani, A., Minai-Tehrani, A., Mirzajani, F., Ghassempour, A., Sadeghi, M. R., ... Rezadoost, H. (2017). Untargeted metabolomic profiling of seminal plasma in nonobstructive azoospermia men: A noninvasive detection of spermatogenesis. Biomedical Chromatography, 31(8), 1-10. https://doi.org/10.1002/bmc.3931

Gilany, K., Moazeni-Pourasil, R. S., Jafarzadeh, N., \& Savadi-Shiraz, E. (2014). Metabolomics fingerprinting of the human seminal plasma of asthenozoospermic patients. Molecular Reproduction and Development, 81(1), 84-86. https://doi.org/10.1002/mrd.22284

Girouard, J., Frenette, G., \& Sullivan, R. (2008). Seminal plasma proteins regulate the association of lipids and proteins within detergent-resistant membrane domains of bovine spermatozoa1. Biology of Reproduction, 78(5), 921-931. https://doi.org/10.1095/ biolreprod.107.066514

Glish, G. L., \& Vachet, R. W. (2003). The basics of mass spectrometry in the twenty-first century. Nature Reviews Drug Discovery, 2(2), 140150. https://doi.org/10.1038/nrd1011

Gu, B., Zhang, J., Wu, Y., Zhang, X., Tan, Z., Lin, Y., Zhang, M. (2011). Proteomic analyses reveal common promiscuous patterns of cell surface proteins on human embryonic stem cells and sperms. PLoS One, 6(5), e19386. https://doi.org/10.1371/journal.pone.0019386

Guo, D., Wu, W., Tang, Q., Qiao, S., Chen, Y., Chen, M., ... Wang, X. (2017). The impact of BMI on sperm parameters and the metabolite changes of seminal plasma concomitantly. Oncotarget, 8(30), 48619-48634. https://doi.org/10.18632/oncotarget.14950

Gupta, A., Mahdi, A. A., Ahmad, M. K., Shukla, K. K., Jaiswer, S. P., \& Shankhwar, S. N. (2011). 1H NMR spectroscopic studies on human seminal plasma: A probative discriminant function analysis classification model. Journal of Pharmaceutical and Biomedical Analysis, 54(1), 106-113. https://doi.org/10.1016/j.jpba.2010.07.021

Gupta, S.., Ghulmiyyah, J.., Sharma, R.., Halabi, J., \& Agarwal, A.. (2014). Power of proteomics in linking oxidative stress and female infertility. BioMed Research International, 2014, 1-26. https://doi. org/10.1155/2014/916212

Hamada, A., Esteves, S. C., Nizza, M., \& Agarwal, A. (2012). Unexplained male infertility: Diagnosis and Management. International Brazilian Journal of Urology, 38(5), 576-594. https://doi.org/10.1590/S1677 $-55382012000500002$

Hamada, A., Sharma, R., Du Plessis, S. S., Willard, B., Yadav, S. P., Sabanegh, E., \& Agarwal, A. (2013). Two-dimensional differential ingel electrophoresis-based proteomics of male gametes in relation to oxidative stress. Fertility and Sterility, 99(5), 1216-1226.e2.

Hamamah, S., Seguin, F., Barthelemy, C., Akoka, S., Le Pape, A., Lansac, J., \& Royere, D. (1993). 1H nuclear magnetic resonance studies of seminal plasma from fertile and infertile men. Journal of Reproduction and Fertility, 97, 51-55. https://doi.org/10.1530/jrf.0.0970051

Hashemitabar, M., Sabbagh, S., Orazizadeh, M., Ghadiri, A., \& Bahmanzadeh, M. (2015). A proteomic analysis on human sperm tail: Comparison between normozoospermia and asthenozoospermia. Journal of Assisted Reproduction and Genetics, 32(6), 853-863. https:// doi.org/10.1007/s10815-015-0465-7

Herwig, R., Knoll, C., Planyavsky, M., Pourbiabany, A., Greilberger, J., \& Bennett, K. L. (2013). Proteomic analysis of seminal plasma from infertile patients with oligoasthenoteratozoospermia due to oxidative stress and comparison with fertile volunteers. Fertility and Sterility, 100(2), 355-366. https://doi.org/10.1016/j.fertn stert.2013.03.048

Hetherington, L., Schneider, E. K., DeKretser, D., Muller, C. H., Hondermarck, H., Velkov, T., \& Baker, M. A. (2016). Deficiency in outer dense fiber 1 is a marker and potential driver of idiopathic male infertility. Molecular and Cellular Proteomics, 15(12), 3685-3693. https://doi.org/10.1074/mcp.M116.060343

Hosseinifar, H., Gourabi, H., Salekdeh, G. H., Alikhani, M., Mirshahvaladi, S., Sabbaghian, M., ... Gilani, M. A. S. (2013). Study of sperm protein profile in men with and without varicocele using two-dimensional gel electrophoresis. Urology, 81(2), 293-300. https://doi.org/10.1016/j. urology.2012.06.027

Hosseinifar, H., Sabbaghian, M., Nasrabadi, D., Modarresi, T., Dizaj, A. V. T., Gourabi, H., \& Gilani, M. A. S. (2014). Study of the effect of varicocelectomy on sperm proteins expression in patients with varicocele and poor sperm quality by using two-dimensional gel electrophoresis. Journal of Assisted Reproduction and Genetics, 31(6), 725-729. https://doi.org/10.1007/s10815-014-0209-0

Huang, Q., Liu, L., Wu, Y., Wang, X., Luo, L., Nan, B., ... Shen, H. (2019). Seminal plasma metabolites mediate the associations of multiple environmental pollutants with semen quality in Chinese 
men. Environment International, 132. https://doi.org/10.1016/j. envint.2019.105066

Intasqui, P., Agarwal, A., Sharma, R., Samanta, L., \& Bertolla, R. P. (2018). Towards the identification of reliable sperm biomarkers for male infertility: A sperm proteomic approach. Andrologia, 50(3), e12919. https://doi.org/10.1111/and.12919

Intasqui, P., Antoniassi, M. P., Camargo, M., Nichi, M., Carvalho, V. M., Morais Cardozo, K. H., ... Pimenta Bertolla, R. (2015). Differences in the seminal plasma proteome are associated with oxidative stress levels in men with normal semen parameters. Fertility and Sterility, 104(2), 292-301. https://doi.org/10.1016/j.fertnstert.2015.04.037

Intasqui, P., Camargo, M., Del Giudice, P. T., Spaine, D. M., Carvalho, V. M., Cardozo, K. H. M., ... Bertolla, R. P. (2013). Unraveling the sperm proteome and post-genomic pathways associated with sperm nuclear DNA fragmentation. Journal of Assisted Reproduction and Genetics, 30(9), 1187-1202. https://doi.org/10.1007/s10815-013-0054-6

Intasqui, P., Camargo, M., Pereira Antoniassi, M., Pereira Cedenho, A., Carvalho, V. M., Morais Cardozo, K. H., ... Pimenta Bertolla, R. (2016). Association between the seminal plasma proteome and sperm functional traits. Fertility and Sterility, 105(3), 617-628. https://doi. org/10.1016/j.fertnstert.2015.11.005

Jafarzadeh, N., Mani-Varnosfaderani, A., Minai-Tehrani, A., Savadi-Shiraz, E., Sadeghi, M. R., \& Gilany, K. (2015). Metabolomics fingerprinting of seminal plasma from unexplained infertile men: A need for novel diagnostic biomarkers. Molecular Reproduction and Development, 82(3), 150. https://doi.org/10.1002/mrd.22457

Jayaraman, V., Ghosh, S., Sengupta, A., Srivastava, S., Sonawat, H. M., \& Narayan, P. K. (2014). Identification of biochemical differences between different forms of male infertility by nuclear magnetic resonance (NMR) spectroscopy. Journal of Assisted Reproduction and Genetics, 31(9), 1195-1204. https://doi.org/10.1007/s1081 5-014-0282-4

Jodar, M., Soler-Ventura, A., \& Oliva, R. (2017). Semen proteomics and male infertility. Journal of Proteomics, 162, 125-134. https://doi. org/10.1016/j.jprot.2016.08.018

Johnston, D. S., Wooters, J., Kopf, G. S., Qiu, Y., \& Roberts, K. P. (2005). Analysis of the human sperm proteome. Annals of the New York Academy of Sciences, 1061, 190-202. https://doi.org/10.1196/ annals.1336.021

Jungwirth, A., Diemer, T., Dohle, G., Kopa, Z., Krausz, C., \& Tournaye, H. (2016). EAU guidelines on male infertility. European Association of Urology, 1-46.

Juo, C. G., Chiu, D. T. Y., \& Shiao, M. S. (2008). Liquid chromatography-mass spectrometry in metabolite profiling. BioFactors, 34(2), 159-169. https://doi.org/10.1002/biof.5520340207

Kanannejad, Z., \& Gharesi-Fard, B. (2019). Difference in the seminal plasma protein expression in unexplained infertile men with successful and unsuccessful in vitro fertilisation outcome. Andrologia, 51(1), e13158. https://doi.org/10.1111/and.13158

Kim, Y. H., Haidl, G., Schaefer, M., Egner, U., Mandal, A., \& Herr, J. C. (2007). Compartmentalization of a unique ADP/ATP carrier protein SFEC (Sperm Flagellar Energy Carrier, AAC4) with glycolytic enzymes in the fibrous sheath of the human sperm flagellar principal piece. Developmental Biology, 302(2), 463-476. https://doi.org/10.1016/j. ydbio.2006.10.004

Lefièvre, L., Chen, Y., Conner, S. J., Scott, J. L., Publicover, S. J., Ford, W. C. L., \& Barratt, C. L. R. (2007). Human spermatozoa contain multiple targets for protein S-nitrosylation: An alternative mechanism of the modulation of sperm function by nitric oxide? Proteomics, 7(17), 3066-3084. https://doi.org/10.1002/pmic.200700254

Leman, E. S., Magheli, A., Yong, K. M. A., Netto, G., Hinz, S., \& Getzenberg, R. H. (2009). Identification of nuclear structural protein alterations associated with seminomas. Journal of Cellular Biochemistry, 108(6), 1274-1279. https://doi.org/10.1002/jcb.22357
Li, J. Y., Liu, F. J., Liu, X., Liu, J., Zhu, P., Wan, F. C., ... Wang, H. Y. (2011). Mapping of the human testicular proteome and its relationship with that of the epididymis and spermatozoa. Molecular and Cellular Proteomics, 10(3), M110.004630. https://doi.org/10.1074/mcp. M110.004630

Liao, T. T., Xiang, Z., Zhu, W. B., \& Fan, L. Q. (2009). Proteome analysis of round-headed and normal spermatozoa by 2-D fluorescence difference gel electrophoresis and mass spectrometry. Asian Journal of Andrology, 11(6), 683-693. https://doi.org/10.1038/aja.2009.59

Lindon, J. C., \& Nicholson, J. K. (2008). Spectroscopic and statistical techniques for information recovery in metabonomics and metabolomics. Annual Review of Analytical Chemistry, 1(1), 45-69. https://doi. org/10.1146/annurev.anchem.1.031207.113026

Liu, M., Hu, Z., Qi, L., Wang, J., Zhou, T., Guo, Y., ... Sha, J. (2013). Scanning of novel cancer/testis proteins by human testis proteomic analysis. Proteomics, 13(7), 1200-1210. https://doi.org/10.1002/pmic.20120 0489

Liu, X., Liu, G., Liu, J., Zhu, P., Wang, J., Wang, Y., Liu, F. (2018). ITRAQbased analysis of sperm proteome from normozoospermic men achieving the rescue-ICSI pregnancy after the IVF failure. Clinical Proteomics, 15(1). https://doi.org/10.1186/s12014-018-9203-3

Liu, X., Wang, W., Zhu, P., Wang, J., Wang, Y., Wang, X., ... Liu, F. (2018). In-depth quantitative proteome analysis of seminal plasma from men with oligoasthenozoospermia and normozoospermia. Reproductive BioMedicine Online, 37(4), 467-479. https://doi.org/10.1016/j. rbmo.2018.06.025

Liu, Y., Zhu, Y., Di, L., Osterberg, E. C., Liu, F., He, L., ... Li, Z. (2014). Raman spectroscopy as an ex vivo noninvasive approach to distinguish complete and incomplete spermatogenesis within human seminiferous tubules. Fertility and Sterility, 102(1), 54-60.e2.

Longo, V., Forleo, A., Provenzano, S. P., Coppola, L., Zara, V., Ferramosca, A., ... Capone, S. (2018). HS-SPME-GC-MS metabolomics approach for sperm quality evaluation by semen volatile organic compounds (VOCs) analysis. Biomedical Physics and Engineering Express, 5(1), 015006. https://doi.org/10.1088/2057-1976/aaeb07

Marco-Ramell, A., Palau-Rodriguez, M., Alay, A., Tulipani, S., Urpi-Sarda, M., Sanchez-Pla, A., \& Andres-Lacueva, C. (2018). Evaluation and comparison of bioinformatic tools for the enrichment analysis of metabolomics data. BMC Bioinformatics, 19(1). https://doi.org/10.1186/ s12859-017-2006-0

Martinez-Heredia, J., de Mateo, S., Vidal-Tboada, J. M., Ballesca, J. L., \& Oliva, R. (2008). Identification of proteomic differences in asthenozoospermic sperm samples. Human Reproduction, 23(4), 783-791. https://doi.org/10.1093/humrep/den024

Martínez-Heredia, J., Estanyol, J. M., Ballescà, J. L., \& Oliva, R. (2006). Proteomic identification of human sperm proteins. Proteomics, 6(15), 4356-4369. https://doi.org/10.1002/pmic.200600094

McReynolds, S., Dzieciatkowska, M., Stevens, J., Hansen, K. C., Schoolcraft, W. B., \& Katz-Jaffe, M. G. (2014). Toward the identification of a subset of unexplained infertility: A sperm proteomic approach. Fertility and Sterility, 102(3), 692-699. https://doi. org/10.1016/j.fertnstert.2014.05.021

Mehrparvar, B., Chashmniam, S., Nobakht, F., Amini, M., Javidi, A., MinaiTehrani, A., Gilany, K. (2020). Metabolic profiling of seminal plasma from teratozoospermia patients. Journal of Pharmaceutical and Biomedical Analysis, 178. https://doi.org/10.1016/j.jpba.2019.112903

Milardi, D., Grande, G., Vincenzoni, F., Messana, I., Pontecorvi, A., De Marinis, L., Marana, R. (2012). Proteomic approach in the identification of fertility pattern in seminal plasma of fertile men. Fertility and Sterility, 97(1), 67-73.e1. https://doi.org/10.1016/j.fertn stert.2011.10.013

Miyaoka, R., \& Esteves, S. C. (2012). A critical appraisal on the role of varicocele in male infertility. Advances in Urology, 597495. https://doi. org/10.1155/2012/597495 
Mumcu, A., Karaer, A., Dogan, B., \& Tuncay, G. (2019). Metabolomics analysis of seminal plasma in patients with idiopathic Oligoasthenoteratozoospermia using high-resolution NMR spectroscopy. Andrology, 1-7.

Murgia, F., Corda, V., Serrenti, M., Usai, V., Santoru, M. L., Hurt, K. J., ... Monni, G. (2020). Seminal fluid metabolomic markers of oligozoospermic infertility in humans. Metabolites, 10(2), 64. https://doi. org/10.3390/metabo10020064

Naaby-Hansen, S., \& Herr, J. C. (2010). Heat shock proteins on the human sperm surface. Journal of Reproductive Immunology, 84(1), 32-40. https://doi.org/10.1016/j.jri.2009.09.006

Newgard, C. B. (2017). Metabolomics and metabolic diseases: Where do we stand? Cell Metabolism, 25(1), 43-56. https://doi.org/10.1016/j. cmet.2016.09.018

Nicholson, J. K., Lindon, J. C., \& Holmes, E. (1999). "Metabonomics": Understanding the metabolic responses of living systems to pathophysiological stimuli via multivariate statistical analysis of biological NMR spectroscopic data. Xenobiotica, 29(11), 1181-1189. https://doi. org/10.1080/004982599238047

Niederberger, C. (2005). Carnitines and male infertility. Journal of Urology, 174(4 Part, 1), 1369. https://doi.org/10.1097/S0022-5347(01)68644 $-0$

Nixon, B., Mitchell, L. A., Anderson, A. L., Mclaughlin, E. A., O'bryan, M. K., \& Aitken, R. J. (2011). Proteomic and functional analysis of human sperm detergent resistant membranes. Journal of Cellular Physiology, 226(10), 2651-2665. https://doi.org/10.1002/jcp.22615

Nowicka-Bauer, K., Ozgo, M., Lepczynski, A., Kamieniczna, M., Malcher A., Skrzypczak, W., \& Kurpisz, M. (2018). Human sperm proteins identified by 2-dimensional electrophoresis and mass spectrometry and their relevance to a transcriptomic analysis. Reproductive Biology, 18(2), 151-160. https://doi.org/10.1016/j.repbio.2018.02.003

Ozkavukcu, S., Erdemli, E., Isik, A., Oztuna, D., \& Karahuseyinoglu, S. (2008). Effects of cryopreservation on sperm parameters and ultrastructural morphology of human spermatozoa. Journal of Assisted Reproduction and Genetics, 25(8), 403-411. https://doi.org/10.1007/ s10815-008-9232-3

Paiva, C., Amaral, A., Rodriguez, M., Canyellas, N., Correig, X., Ballescà, J. L., ... Oliva, R. (2015). Identification of endogenous metabolites in human sperm cells using proton nuclear magnetic resonance $(1 \mathrm{H}-$ NMR) spectroscopy and gas chromatography-mass spectrometry (GC-MS). Andrology, 3(3), 496-505.

Panner Selvam, M. K., \& Agarwal, A. (2018). Update on the proteomics of male infertility: A systematic review. Arab Journal of Urology, 16(1), 103-112. https://doi.org/10.1016/j.aju.2017.11.016

Panner Selvam, M. K., \& Agarwal, A. (2019). Proteomic profiling of seminal plasma proteins in varicocele patients. The World Journal of Men's Health, 37.

Panner Selvam, M., Agarwal, A., \& Baskaran, S. (2019). Proteomic analysis of seminal plasma from bilateral varicocele patients indicates an oxidative state and increased inflammatory response. Asian Journal of Andrology, 21(6), 544-550. https://doi.org/10.4103/aja.aja_121_18

Panner Selvam, M. K., Agarwal, A., Dias, T. R., Martins, A. D., Baskaran, S., \& Samanta, L. (2019). Molecular pathways associated with sperm biofunction are not affected by the presence of round cell and leukocyte proteins in human sperm proteome. Journal of Proteome Research, 18(3), 1191-1197. https://doi.org/10.1021/acs.jproteome.8b00829

Panner Selvam, M. K., Agarwal, A., Dias, T. R., Martins, A. D., \& Samanta, L. (2019). Presence of round cells proteins do not interfere with identification of human sperm proteins from frozen semen samples by LC-MS/MS. International Journal of Molecular Sciences, 20(2). https:// doi.org/10.3390/ijms20020314

Panner Selvam, M. K., Agarwal, A., \& Pushparaj, P. N. (2019). A quantitative global proteomics approach to understanding the functional pathways dysregulated in the spermatozoa of asthenozoospermic testicular cancer patients. Andrology, 7(4), 454-462.
Panner Selvam, M. K., Agarwal, A., Pushparaj, P. N., Baskaran, S., \& Bendou, H. (2019). Sperm proteome analysis and identification of fertility-associated biomarkers in unexplained male infertility. Genes, 10(7). https://doi.org/10.3390/genes10070522

Parte, P. P., Rao, P., Redij, S., Lobo, V., D'Souza, S. J., Gajbhiye, R., \& Kulkarni, V. (2012). Sperm phosphoproteome profiling by ultra performance liquid chromatography followed by data independent analysis (LC-MSE) reveals altered proteomic signatures in asthenozoospermia. Journal of Proteomics, 75(18), 5861-5871. https://doi. org/10.1016/j.jprot.2012.07.003

Patti, G. J., Yanes, O., \& Siuzdak, G. (2012). Metabolomics: The apogee of the omics trilogy. Nature Reviews Molecular Cell Biology, 13(4), 263269. https://doi.org/10.1038/nrm3314

Pilch, B., \& Mann, M. (2006). Large-scale and high-confidence proteomic analysis of human seminal plasma. Genome Biology, 7(5).

Qiao, S., Wu, W., Chen, M., Tang, Q., Xia, Y., Jia, W., \& Wang, X. (2017). Seminal plasma metabolomics approach for the diagnosis of unexplained male infertility. PLoS One, 12(8), 1-13. https://doi. org/10.1371/journal.pone.0181115

Reynolds, S., Calvert, S. J., Paley, M. N., \& Pacey, A. A. (2017). 1H magnetic resonance spectroscopy of live human sperm. Molecular Human Reproduction, 23(7), 441-451. https://doi.org/10.1093/molehr/gax025

Rødgaard, T., Heegaard, P. M. H., \& Callesen, H. (2015). Non-invasive assessment of in-vitro embryo quality to improve transfer success. Reproductive BioMedicine Online, 31(5), 585-592. https://doi. org/10.1016/j.rbmo.2015.08.003

Sadowski, P. G., Dunkley, T. P. J., Shadforth, I. P., Dupree, P., Bessant, C., Griffin, J. L., \& Lilley, K. S. (2006). Quantitative proteomic approach to study subcellular localization of membrane proteins. Nature Protocols, 1(4), 1778-1789. https://doi.org/10.1038/nprot.2006.254

Salehi, M., Akbari, H., Heidari, M. H., Molouki, A., Murulitharan, K., Moeini, H., ... Heidari, R. (2013). Correlation between human clusterin in seminal plasma with sperm protamine deficiency and DNA fragmentation. Molecular Reproduction and Development, 80(9), 718724. https://doi.org/10.1002/mrd.22202

Samanta, L., Agarwal, A., Swain, N., Sharma, R., Gopalan, B., Esteves, S. C., ... Sabanegh, E. (2018). Proteomic signatures of sperm mitochondria in varicocele: Clinical use as biomarkers of varicocele associated infertility. Journal of Urology, 200(2), 414-422. https://doi. org/10.1016/j.juro.2018.03.009

Samanta, L., Sharma, R., Cui, Z., \& Agarwal, A. (2018). Proteomic analysis reveals dysregulated cell signaling in ejaculated spermatozoa from infertile men. Asian Journal of Andrology, 20, 1-10.

Samanta, L., Swain, N., Ayaz, A., Venugopal, V., \& Agarwal, A. (2016). Post-translational modifications in sperm proteome: The chemistry of proteome diversifications in the pathophysiology of male factor infertility. Biochimica Et Biophysica Acta, 1860(7), 1450-1465. https:// doi.org/10.1016/j.bbagen.2016.04.001

Sharma, R., Agarwal, A., Mohanty, G., Hamada, A. J., Gopalan, B., Willard, B., du Plessis, S. (2013). Proteomic analysis of human spermatozoa proteins with oxidative stress. Reproductive Biology and Endocrinology, 11(1). https://doi.org/10.1186/1477-7827-11-48

Shen, S., Wang, J., Liang, J., \& He, D. (2013). Comparative proteomic study between human normal motility sperm and idiopathic asthenozoospermia. World Journal of Urology, 31(6), 1395-1401. https:// doi.org/10.1007/s00345-013-1023-5

Shetty, J., Diekman, A. B., Jayes, F. C. L., Sherman, N. E., Naaby-Hansen, S., Flickinger, C. J., \& Herr, J. C. (2001). Differential extraction and enrichment of human sperm surface proteins in a proteome: Identification of immunocontraceptive candidates. Electrophoresis, 22(14), 3053-3066. https://doi.org/10.1002/1522-2683(20010 8)22:14<3053:AID-ELPS3053>3.0.CO;2-K

Sinha, A., Singh, V., \& Yadav, S. (2017). Multi-omics and male infertility: Status, integration and future prospects. Frontiers in Bioscience Scholar, 9(3), 375-394. https://doi.org/10.2741/s493 
Siva, A. B., Kameshwari, D. B., Singh, V., Pavani, K., Sundaram, C. S., Rangaraj, N., ... Shivaji, S. (2010). Proteomics-based study on asthenozoospermia: Differential expression of proteasome alpha complex. Molecular Human Reproduction, 16(7), 452-462. https://doi.org/10.1093/molehr/gaq009

Stein, K. K., Go, J. C., Lane, W. S., Primakoff, P., \& Myles, D. G. (2006). Proteomic analysis of sperm regions that mediate sperm-egg interactions. Proteomics, 6(12), 3533-3543. https://doi.org/10.1002/ pmic. 200500845

Swain, N., Samanta, L., Agarwal, A., Kumar, S., Dixit, A., Gopalan, B., Baskaran, S. (2019). Aberrant upregulation of compensatory redox molecular machines may contribute to sperm dysfunction in infertile men with unilateral varicocele: A proteomic insight. Antioxidants \& Redox Signaling, ars.2019.7828.

Tang, B., Shang, X., Qi, H., Li, J., Ma, B., An, G., \& Zhang, Q. (2017). Metabonomic analysis of fatty acids in seminal plasma between healthy and asthenozoospermic men based on gas chromatography mass spectrometry. Andrologia, 49(9), 1-13. https://doi.org/10.1111/ and.12744

Vigodner, M., Shrivastava, V., Gutstein, L., Schneider, J., Nieves, E., Goldstein, M., ... Callaway, M. (2013). Localization and identification of sumoylated proteins in human sperm: Excessive sumoylation is a marker of defective spermatozoa. Human Reproduction, 28(1), 210223. https://doi.org/10.1093/humrep/des317

Vivanco, F., Barderas, M. G., Laborde, C. M., Posada, M., De La Cuesta, F., Zubiri, I., \& Alvarez-Llamas, G. (2011). Metabolomic profiling for identification of novel potential biomarkers in cardiovascular diseases. Journal of Biomedicine and Biotechnology, 2011.

Wang, G., Wu, Y., Zhou, T., Guo, Y., Zheng, B., Wang, J., ... Sha, J. (2013). Mapping of the $\mathrm{N}$-linked glycoproteome of human spermatozoa. Journal of Proteome Research, 12(12), 5750-5759. https://doi. org/10.1021/pr400753f

Wang, S., Wang, W., Xu, Y., Tang, M., Fang, J., Sun, H., ... Yin, C. (2014). Proteomic characteristics of human sperm cryopreservation. Proteomics, 14(2-3), 298-310. https://doi.org/10.1002/pmic.20130 0225

Wang, X. M., Xiang, Z., Fu, Y., Wu, H. L., Zhu, W. B., \& Fan, L. Q. (2018). Comparative proteomics reveal the association between SPANX proteins and clinical outcomes of artificial insemination with donor sperm. Scientific Reports, 8(1). https://doi.org/10.1038/s41598-01825032-4

Wishart, D. S., Jewison, T., Guo, A. C., Wilson, M., Knox, C., Liu, Y., ... Scalbert, A. (2013). HMDB 3.0-The human metabolome database in 2013. Nucleic Acids Research, 41, D801-D807.

Xu, W., Hu, H., Wang, Z., Chen, X., Yang, F., Zhu, Z., ... Qiao, Z. (2012). Proteomic characteristics of spermatozoa in normozoospermic patients with infertility. Journal of Proteomics, 75(17), 5426-5436. https://doi.org/10.1016/j.jprot.2012.06.021

Xu, Y., Lu, H., Wang, Y., Zhang, Z., \& Wu, Q. (2020). Comprehensive metabolic profiles of seminal plasma with different forms of male infertility and their correlation with sperm parameters. Journal of Pharmaceutical and Biomedical Analysis, 177, 112888 https://doi. org/10.1016/j.jpba.2019.112888

Yamakawa, K., Yoshida, K., Nishikawa, H., Kato, T., \& Iwamoto, T. (2007). Comparative analysis of interindividual variations in the seminal plasma proteome of fertile men with identification of potential markers for azoospermia in infertile patients. Journal of Andrology, 28(6), 858-865. https://doi.org/10.2164/jandrol.107.002824

Yang, H., \& Geiger, M. (2017). Cell penetrating SERPINA5 (Protein C inhibitor, $\mathrm{PCl}$ ): More questions than answers. Seminars in Cell and Developmental Biology, 62, 187-193. https://doi.org/10.1016/j. semcdb.2016.10.007

Yu, L., Yang, X., Ma, B., Ying, H., Shang, X., He, B., \& Zhang, Q. (2019). Abnormal arachidonic acid metabolic network may reduce sperm motility via P38 MAPK. Open Biology, 9(4). https://doi.org/10.1098/ rsob.180091
Zamboni, N., Saghatelian, A., \& Patti, G. J. (2015). Defining the metabolome: Size, flux, and regulation. Molecular Cell, 58(4), 699-706. https://doi.org/10.1016/j.molcel.2015.04.021

Zhang, A., Sun, H., Wang, P., Han, Y., \& Wang, X. (2012). Recent and potential developments of biofluid analyses in metabolomics. Journal of Proteomics, 75(4), 1079-1088. https://doi.org/10.1016/j. jprot.2011.10.027

Zhang, J., Huang, Z., Chen, M., Xia, Y., Martin, F. L., Hang, W., \& Shen, H. (2014). Urinary metabolome identifies signatures of oligozoospermic infertile men. Fertility and Sterility, 102(1), 44-53.e12. https://doi. org/10.1016/j.fertnstert.2014.03.033

Zhang, J., Mu, X., Xia, Y., Martin, F. L., Hang, W., Liu, L., ... Shen, H. (2014). Metabolomic analysis reveals a unique urinary pattern in normozoospermic infertile men. Journal of Proteome Research, 13(6), 30883099. https://doi.org/10.1021/pr5003142

Zhang, X., Diao, R., Zhu, X., Li, Z., \& Cai, Z. (2015). Metabolic characterization of asthenozoospermia using nontargeted seminal plasma metabolomics. Clinica Chimica Acta, 450, 254-261. https://doi. org/10.1016/j.cca.2015.09.001

Zhao, C., Huo, R., Wang, F. Q., Lin, M., Zhou, Z. M., \& Sha, J. H. (2007). Identification of several proteins involved in regulation of sperm motility by proteomic analysis. Fertility and Sterility, 87(2), 436-438. https://doi.org/10.1016/j.fertnstert.2006.06.057

Zhao, K., Zhang, J., Xu, Z., Xu, Y., Xu, A., Chen, W., Jia, R. (2018). Metabolomic profiling of human spermatozoa in idiopathic Asthenozoospermia patients using gas chromatography-mass spectrometry. BioMed Research International, 2018, 1-8. https://doi. org/10.1155/2018/8327506

Zhou, M., \& Philips, M. R. (2017). Nitrogen cavitation and differential centrifugation allows for monitoring the distribution of peripheral membrane proteins in cultured cells. Journal of Visualized Experiments : Jove, 126, 56037.

Zhou, T., Zhou, Z. M., \& Guo, X. J. (2013). Bioinformatics for spermatogenesis: Annotation of male reproduction based on proteomics. Asian Journal of Andrology, 15(5), 594-602. https://doi.org/10.1038/ aja.2013.67

Zhou, X., Wang, Y., Yun, Y., Xia, Z., Lu, H., Luo, J., \& Liang, Y. (2016). A potential tool for diagnosis of male infertility: Plasma metabolomics based on GC-MS. Talanta, 147, 82-89. https://doi.org/10.1016/j.talan ta.2015.09.040

Zimmermann, U., Junker, H., Krämer, F., Balabanov, S., Kleist, B., Kammer, W., ... Walther, R. (2006). Comparative proteomic analysis of neoplastic and non-neoplastic germ cell tissue. Biological Chemistry, 387(4), 437-440. https://doi.org/10.1515/BC.2006.058

Zylbersztejn, D. S., Andreoni, C., Del Giudice, P. T., Spaine, D. M., Borsari, L., Souza, G. H. M. F., ... Fraietta, R. (2013). Proteomic analysis of seminal plasma in adolescents with and without varicocele. Fertility and Sterility, 99(1), 92-98. https://doi.org/10.1016/j.fertn stert.2012.08.048

How to cite this article: Panner Selvam MK, Finelli R, Agarwal

A, Henkel R. Proteomics and metabolomics - Current and future perspectives in clinical andrology. Andrologia. 2021;53:e13711. https://doi.org/10.1111/and.13711 